\title{
Arteriovenous Malformation of the Uterus: A Review and Update.
}

\author{
Anthony Kodzo-Grey Venyo ${ }^{1 *}$, Emad Bakir ${ }^{2}$ \\ ${ }^{1}$ North Manchester General Hospital, Department of Urology, Manchester, United Kingdom. \\ ${ }^{2}$ Department of Radiology, Hamad Medical Corporation, Doha, Qatar.
}

Corresponding author: Anthony Kodzo-Grey Venyo, North Manchester General Hospital, Department of Urology, Manchester, United Kingdom.

Received date: June 18, 2021; Accepted date: August 20, 2021; Published date: October 02, 2021

Citation: Anthony K.G.Venyo, Emad Bakir (2021) Arteriovenous Malformation of the Uterus: A Review and Update J. Obstetrics Gynecology and Reproductive Sciences 5(8) DOI:10.31579/2578-8965/085

Copyright: () 2021, Anthony Kodzo-Grey Venyo, This is an open access article distributed under the Creative Commons Attribution License, which permits unrestricted use, distribution, and reproduction in any medium, provided the original work is properly cited.

\begin{abstract}
Arteriovenous malformation of the uterus (AVMU) is a very rare and uncommon condition, because it has been documented that less than 100 cases of AVMU have been reported in the literature. AVMU is potentially a life-threatening condition with regard to the fact that some cases of AVMU could manifest with profuse bleeding from the uterus via the vagina. AVMU could either be congenital AVMU which is less common or acquired AVMU with pregnancy noted to have a role to play in the pathogenesis of AVMUs. The true incidence of AVMU is stated to be difficult to ascertain in view of the fact that some cases of bleeding that have been caused by AVMU do tend to conservative, medical management and many of these AVMUs could remain undiagnosed. The most common manifestations of AVMUs tend to be abnormal uterine bleeding that could be episodic, intermittent, continuous, mild or torrential which could lead to severe anaemia or shock. Some AVMUs could be found incidentally based upon radiology imaging for a different condition. Other symptoms of AVMUs do include: Metrorrhagia; Menorrhagia; Bleeding following a miscarriage; Bleeding following dilatation and curettage; Bleeding subsequently after hysterectomy; Bleeding associated with trophoblastic disease; Bleeding following caesarean section; Post-partum haemorrhage; Intermittent vaginal bleeding; Continuous vaginal bleeding; Post-menopausal bleeding; Acute abdominal pain with hemoperitoneum; Pallor; Dizziness; Weakness; Drowsiness; Being unwell following delivery of a baby; Bleeding following therapeutic abortion; Tachycardia; Supra-pubic pain at times; hypotension. Diagnosis of AVMU tends to be made based upon radiology imaging with utilization of ultrasound scan / Doppler scan of the uterus and pelvis, Contrast Computed Tomography scan, and Contrast Magnetic Resonance Imaging Scan, as well as by selective angiography which tends to be ensued by treatment with embolization of the feeding vessels to the AVMU. The treatment of AVMUs these days has ranged between conservative and medical management that includes hormones for small AVMUs, Hysterectomy, which tends to be a definitive treatment that removes the AVMU but does leave the individual not being able to maintain her future fertility, as well as selective angiography and super-selective embolization of the uterine arterial branches feeding the AVMU, which does tend to maintain the future fertility of the patients and which has the advantage of being undertaken under local anaesthesia. Questions that should be on the minds of clinicians include should doppler ultrasound scan of the uterus be undertaken with regard to all women who develop persistent vaginal bleeding pursuant to or during management of miscarriage, considering that there are very few interventional radiologists in many hospitals. This means that selective angiography plus super-selective embolization cannot be undertaken in district hospitals should all women who have suspected AVMU that have severe bleeding that may require surgical operation be referred to a tertiary hospital so that they could possibly benefit from the undertaking of selective angiography and embolization of their AVMUs instead of hysterectomy to enable them to maintain their future fertility? It is also important for clinicians to be made aware of the existence of AVMUs so that they could appreciate the risk factors as well as the clinical manifestations who should be suspected of possibly having AVMUs. Clinicians also need to learn about various conservative and expectant methods of treating AVMUs including hormonal treatment. Clinicians also need to appreciate the future implications for future fertility of women who have AVMUs. Possible treatment options that have not been utilized for the treatment of AVMUs include: (a) Radiology image-guided cryotherapy of AVMU, (b) Radiology image-guided radiofrequency ablation of AVMU, and (c) Radiology Image-guided Irreversible electroporation of AVMU. There is a global need for the training of more interventional radiologists all over the world including in the developing countries as well as some of the developed countries to that they can undertake embolization of AVMUs as well as they can provide various interventional radiology treatment options for various other conditions.
\end{abstract}


Key Words: arteriovenous malformation; abnormal uterine bleeding; shock; ultrasound scan; doppler ultrasound; contrast computed tomography scan; contrast magnetic resonance imaging scan, selective angiography; super-selective embolization; uterine artery; preservation; fertility; hysterectomy; conservative management; medical management; hormonal treatment

\section{Introduction}

Arteriovenous malformation of the uterus (AVMU) is a term that is utilized for an abnormal and non-functional connections between uterine arteries and uterine veins. [1] Arteriovenous malformations of the uterus can either be congenital AVMUs or acquired AVMUs, which tend to be traumatic lesions. [1] It has been iterated that congenital AVMUs tend to be very rarely encountered, but on the other hand, the incidence of acquired AVMUs has been noted to be currently. Increasing. [1] [2] [3] [4] It has been documented that acquired AVMUs often tend to be linked with the undertaking of previous surgery to the uterus that had tended quite often to be dilatation and curettage $(\mathrm{D} / \mathrm{C})$ procedure, therapeutic abortion, carcinoma of the cervix or carcinoma of the endometrium, trophoblastic diseases, as well as pursuant to direct trauma to the uterus and this has tended to be encountered more commonly with regard to women who are within their reproductive ages. [1] [5] It has been iterated that the typical symptom of AVMU has tended to be bleeding from the vagina; nevertheless, some patients could manifest with life-threatening massive bleeding. [1] It has been postulated that congenital AVMUs do arise from arrested vascular embryological development that emanate in anomalous differentiation within the capillaries as well as abnormal communication, between the arteries and the veins. [1] [6] It has additionally been documented that congenital AVMUs could have multiple vascular connections and they could invade encompassing structures. [1] It has been iterated that it is pertinent to diagnose AVMU correctly in order to commence an effective and appropriate treatment quickly, in view of the fact that AVMU often has tended to be ensued by life-threatening severe bleeding from the vagina. [1] It has been documented that in the current modern era, AVMU has tended to be diagnosed based upon Colour Doppler ultrasound scan. [1] [7] Despite this it has also been pointed out that, with regard to the differential diagnoses of AVMU, retained products of conception (RPOC), as well as gestational trophoblastic diseases (GTD) need to be considered in view of the fact that these cases could also depict a hyper-vascular appearing feature associated with turbulent flow. [1] It has been iterated that the assessment of levels of serum Beta Chorionic Gonadotrophin (ß-HCG), could be beneficial with regard to the diagnosis. [1] Whilst it may be possible to utilize Doppler ultrasound scan to diagnose AVMU in the hospitals within the developed world, it is possible that smaller district hospitals in some of the developing countries may not have facilities or well-trained staff, who would be helpful with regard to the diagnosis of AVMU. It has been iterated that the treatment of AVMU has tended to change depending upon the age of the patient, the desire of the patient to continue having future fertility, the location of the AVMU, as well as the size of the AVMU. [1] It has been documented that the common options of management of AVMU have tended to be hysterectomy or by embolization of uterine arteries. [1] Considering that there are very few interventional radiologists in many hospitals of some developing countries, there would be no facilities and staff to undertake embolization of uterine arteries in these hospitals and thus severe bleeding from AVMUs in such hospitals may be limited to hysterectomy only which end the chance of the patient being pregnant again. Nevertheless, it has been stated that uterine artery angiography and super-selective embolization of arterial branches of the uterine arteries does remain the first treatment option of choice with regard to women who are within their reproductive age and who have the expectation of having or ensuring they maintain their fertility in the future. [8] It has been stated that whether the undertaking of embolization of the uterine artery is safe for women who have the desire to maintain their future fertility has been controversial; nevertheless, women who become pregnant are pursuant to undergoing embolization of their uterine arteries have been stated to have the risk of having malpresentation of their babies, undergoing caesarean section delivery of their babies, delivering pre-term babies, as well as developing post-partum haemorrhages. [1] [9] Some studies had indicated that the undertaking of conservative management of AVMU could be an appropriate management to be adopted for patients who are asymptomatic. [10] [11] Other studies on AVMU have also documented utilization of methylergonovine maleate, gonadotrophin releasing hormone analogues, as well as using danazol in the management of the patients who manifest with mild haemorrhage. [12] [13] [14] It has been iterated that there is no consensus opinion regarding the management of individuals who have asymptomatic AVMUs. [1] The ensuing article on arteriovenous malformations of the uterus (AVMUs) is divided into two parts (A) Overview that has discussed miscellaneous general points related to AVMUs and (B) Miscellaneous narrations and discussions from some case reports, case series, and studies related to AVMUs.

\section{Aim:}

To review and update the literature on arteriovenous malformations of the uterus (AVMUs).

\section{Method:}

Internet data bases were searched including Google: Google Scholar; Yahoo; and PUBMED. Thirty-eight references were identified which were used to write the article that has been divided into two parts (A) Overview and (B) Miscellaneous narrations and discussions from case reports, case series and studies related to arteriovenous malformations of the uterus.

\section{Results / Literature Review \\ (A) Overview}

Definition / General statements.

- It has been documented that Arteriovenous Malformations (AVMs) is terminology that is utilized for congenital lesions that are composed of a complex tangle of arteries and veins that have been connected by one or more fistula. Arteriovenous malformations are stated to most often occur in young adults in who morbidity and death do occur in $30 \%$ to $50 \%$ and $10 \%$ to $15 \%$ of patients respectively. [15]

- Arteriovenous malformation can occur in any organ of the body.

- Arteriovenous malformation of the uterus (AVMU) is a term which is utilized for abnormal and non-functional connections between the uterine arteries and uterine veins. It has been iterated that, even though patients who have AVMU typically tend to manifest with bleeding from the vagina, some patients who have AVMU could experience life-threatening massive bleeding. [1]

Presentation

Some of the presentations of AVMUs would include:

- Incidental diagnosis upon radiology imaging for something else.

- Vaginal bleeding which could be in the form of: - Metrorrhagia 

Menorrhagia
Bleeding following a miscarriage
Bleeding following dilatation and curettage
Bleeding subsequently after hysterectomy
Bleeding associated with trophoblastic disease.
Bleeding following caesarean section.
Post-partum haemorrhage
Intermittent vaginal bleeding
Continuous vaginal bleeding
Post-menopausal bleeding
Acute abdominal pain with hemoperitoneum.

- Pallor

- Dizziness

- Weakness

- Drowsiness

- Being unwell following delivery of a baby

- Bleeding following therapeutic abortion.

- Tachycardia

- $\quad$ Supra-pubic pain at times.

- Hypotension

Clinical Examination findings

The general and systematic examination of individuals who have AVMU would tend to be normal and abdominal examination would also tend to be normal. Nevertheless, in cases of severe bleeding there may be evidence of pallor, tachycardia, reflecting anaemia. Vagina examination / hysteroscopy may demonstrate blood exuding through the os of the cervix indicating bleeding from the uterine cavity.

\section{Laboratory investigations}

Urine

Urinalysis, urine microscopy and culture tend to be undertaken as part of the general assessment of individuals who have AVMU but generally there would be no evidence of urinary tract infection; however, if there is evidence of urinary tract infection it would be treated appropriately to improve upon the general condition of the patient. During episodes of vaginal bleeding related to AVMU, there could be evidence of red blood cells in the urine of the patient.

Haematology blood tests

Full blood count, INR, and coagulation studies tend to be undertaken in cases of AVMU but usually in uncomplicated cases of AVMU, the results of the routine haematology blood tests would tend to be normal. With regard to AVMU associated with severe bleeding there could be evidence of anaemia which the clinician would need to treat in order to improve upon the general condition of the patient.

Biochemistry blood tests

Serum urea, EGFR electrolytes (routine renal function tests), blood glucose, and liver function tests are routine biochemistry that tend to be undertaken in the general assessment of individuals who have AVMU and generally these results would tend to be normal, but if there is any abnormality detected in the routine blood biochemistry tests it would be investigated and appropriate treatment would be provided to improve upon the general condition of the patient.

Beta-Human Chorionic Gonadotrophin (B-HCG)

- Serum (B-HCG) tends to be undertaken in individuals who present bleeding from the uterus

Radiology investigations

Ultrasound scan

- Ultrasound of the pelvic organs is a routine radiology imaging that tends to be undertaken in all patients who manifest with uterine bleeding and Doppler ultrasound scan of the uterus would tend to demonstrate AVMU in many cases of AVMU.
- Grey scale ultrasound scan could demonstrate presence of multiple tubular or "spongy" anechoic or hypo-echoic areas within the myometrium of a normal endometrium.

- Trans-abdominal ultrasound scan of the pelvis could demonstrate increased vascularity with multi-directional flow of the uterus as well as prominent vessels located on the wall of the uterus. If there is a retained product of conception this would also be demonstrated by the ultrasound scan.

Contrast-enhanced Computed Tomography (CE-CT) Scan

- CE-CT scan of the pelvic organs with angiography imaging of the pelvic organs is a routine radiology imaging that tends to be undertaken in all patients who manifest with uterine bleeding and this would tend to demonstrate AVMU in many cases of AVMU.

Contrast-enhanced Magnetic Resonance Imaging (CE-MRI) scan

- CE-MRI scan of the pelvic organs with angiography imaging of the pelvic organs is a routine radiology imaging that tends to be undertaken in all patients who manifest with uterine bleeding and this would tend to demonstrate AVMU in many cases of AVMU.

Selective angiography

- Selective angiography in cases of AVMU does demonstrate AVMU and based upon confirmation of the AVMU embolization of the AVMU tends to be undertaken under local anaesthesia which tends quite often to stop the bleeding from the AVMU. In cases of large AVMUs, the size of the AVMU would typically reduce and there may be residual AVMUs. Recurrences of AVMUs could develop subsequently in some cases of AVMU.

Treatment

Various treatment options have been adopted depending upon the age of the patient, the size of the AVMU, the location of the AVMU, the desire of the patient to maintain her future fertility and these options have included:

- Expectant / conservative management and Medical management.

- Hysterectomy for severe massive / incessant bleeding.

- Selective angiography and super-selective embolization of the feeding arteries of AVMU in centres where there is an interventional radiologist.

Differential Diagnoses

Some of the differential diagnosis of AVMU include:

- $\quad$ Retained products of conception.

- Gestational trophoblastic disease

- Haemangioma

Outcome

- Conservative and medical management of AVMU has been successful with regard to the outcome of some small cases of AVMU.

- Hysterectomy has been curative with regard to the resolution of AVMUs; nevertheless, this has been associated with loss of fertility of each individual.

- Selective angiography and super-selective embolization of AVMU which tends to be taken under local anaesthesia and is typically associated with good outcome which has avoided hysterectomy, and which also has tended to be associated with maintenance of future fertility of the individuals who have undergone embolization of their AVMUs. Future recurrence of AVMU has been reported which can further be treated by means of further embolization and with regard to small recurrences medical management could be undertaken. In the scenario of an excessive uterine bleeding which has not been 
controlled or stopped by embolization of the uterine artery feeding vessels of the AVMU, hysterectomy can be undertaken as a last resort which would mean that the future fertility of the patient would be lost.

\section{(B) Miscellaneous narrations and discussions from some case reports, case series, and studies related to arteriovenous malformations of the uterus.}

Shintre and Coelho [16] reported a 27-year-old lady who was known to have Thalassemia minor who had manifested with heavy vaginal bleeding and passage of clots over the preceding two days. She stated that she had been having continuous on and off mild to moderate vaginal bleeding pursuant to a second trimester therapeutic abortion she had undergone two months preceding her presentation. She did undergo therapeutic abortion in view of the fact that she had her chorionic venous samples which had shown that the foetus had Thalassemia major due to the fact that both herself and her husband had Thalassemia minor. The therapeutic abortion was induced with utilization of misoprostol (PGE1) tablets. The reports of the obstetrician who undertook the therapeutic abortion did document that the abortion was complete and therefore no curettage was undertaken pursuant to her abortion. She had also undergone another therapeutic abortion 8 months earlier for the same reason following chorionic villous sampling that showed Thalassemia major foetus. This therapeutic abortion was ensued by curettage of her uterine cavity for complete evacuation of her products of conception. She did not have any significant past medical or surgical history. She was noted to be pale or otherwise her general examination was normal. She had speculum examination of her vagina which showed a partially open cervical os that associated with minimal blood clots. There was no active bleeding. Her uterus was bulky, and it measured about 8 weeks to 10 weeks size as well as it was firm to soft in consistency, firm to soft with regard to consistency, mobile and associated with free fornices. The results of some of his laboratory blood tests included: Haemoglobin 9.5 grams per decilitre, platelets 3-lakhs, Serum Beta Human Chorionic Gonadotrophin (B-HCG) 35 MIU/ML which was normal, normal coagulation screen and normal liver function tests. Her blood sample was sent for grouping and saving for future use when required. She had ultrasound scan and magnetic resonance imaging (MRI) of pelvis. The MRI scan demonstrated a bulky uterus that measured $4 \mathrm{~cm} \times 7 \mathrm{~cm} \times 7 \mathrm{~cm}$, heterogeneous lesion within the posterior wall of her uterus, lost endometrial-myometrial interface, multiple dilated tortuous blood vessels within her posterior myometrium which had suggested the likelihood of retained products of conception or gestational trophoblastic tumour which would represent placental site trophoblastic tumour, or uterine vascular malformation (see figure 1). The trans-abdominal ultrasound scan of pelvis did demonstrate an $8.8 \mathrm{~cm} \times 7.5 \mathrm{~cm} \times 7.5 \mathrm{~cm}$ bulky uterus the posterior myometrium that was very enlarged as well as heterogeneous with increased vascularity upon Doppler ultrasound scanning (see figure 2). Doppler ultrasound scanning did demonstrate a peak systolic velocity (PSV) of $121 \mathrm{~cm} / \mathrm{s}$ as well as restrictive index of 0.36. The ultrasound scan also demonstrated that her endometrium was thickened within the lower uterine segment that was suggestive of retained products of conception. She had a chest x-ray which was normal. She had ultrasound scan-guided evacuation of her retained products of conception from her lower uterine segment which was sent for pathology examination. The evacuation of the products of conception did trigger active bleeding. She therefore underwent uterine artery embolization with utilization of cyanoacrylate (glue) (see figure 3). There was no evidence of active bleeding pursuant to her embolization. She was discharged on the $3^{\text {rd }}$ post-procedure op day on oral antibiotics and haematinics. Pathology examination of the tissue did show degenerated and necrosed bits of decidua as well as few degenerate chorionic villi that were admixed with fibrin and blood. The degenerate products of conception did not show pathology examination features of placental site tumour trophoblastic. At her 6-weeks follow-up assessment she stated that her vaginal bleeding had diminished gradually over a period of 4 weeks and the bleeding stopped completely after 4 weeks. She had ultrasound scan of her pelvis with Doppler scan which did show diminished size of the arteriovenous fistula and with diminished vascularity (see figure 4). Shintre et al. [16] stated that the first case of AVM of the uterus was reported in 1926. [17]

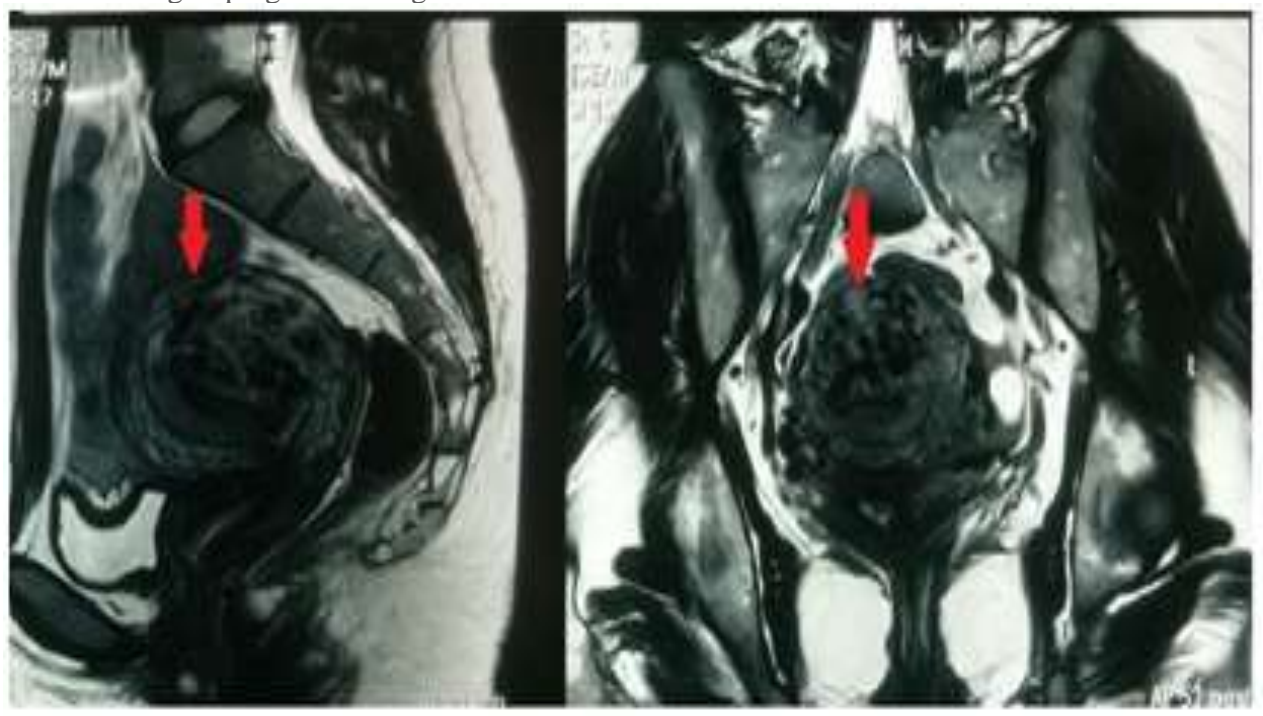

Figure 1:

MRI pelvis-sagittal and transverse section-showing bulky uterus with $4 \times 7 \times 7 \mathrm{~cm}$ sized heterogeneous lesion seen in posterior wall, lost endometrial-myometrial interface, multiple dilated tortuous blood vessels in posterior myometrium \& tiny enhancing area within the endometrium in lower uterine segment. Reproduced from: [16] Shintre H S, Coelho K S. Managing Uterine Arteriovenous Malformation (AVM) Is Like Dealing with Raging Wildfire Awaiting A Spark: Better Be Extremely Cautious \& Be Ready with Counter Measures Like Uterine Artery Embolization (UAE). Obstet. Gynecol. Int. J. 2017; 6(1): 00195 DOI: 10.15406/ogij:2017.06.00195 
https://medcraveonline.com/OGIJ/managing-uterine-arteriovenous-malformation-avm-is-like-dealing-with-raging-wildfire-awaiting-a-spark-betterbe-extremely-cautious-amp-be-ready-with-countermeasures-like-uterine-artery-embolization-uae.html under copy right (O2017 Shintre, et al. This is an open access article distributed under the terms of the, which permits unrestricted use, distribution, and build upon your work non-commercially.

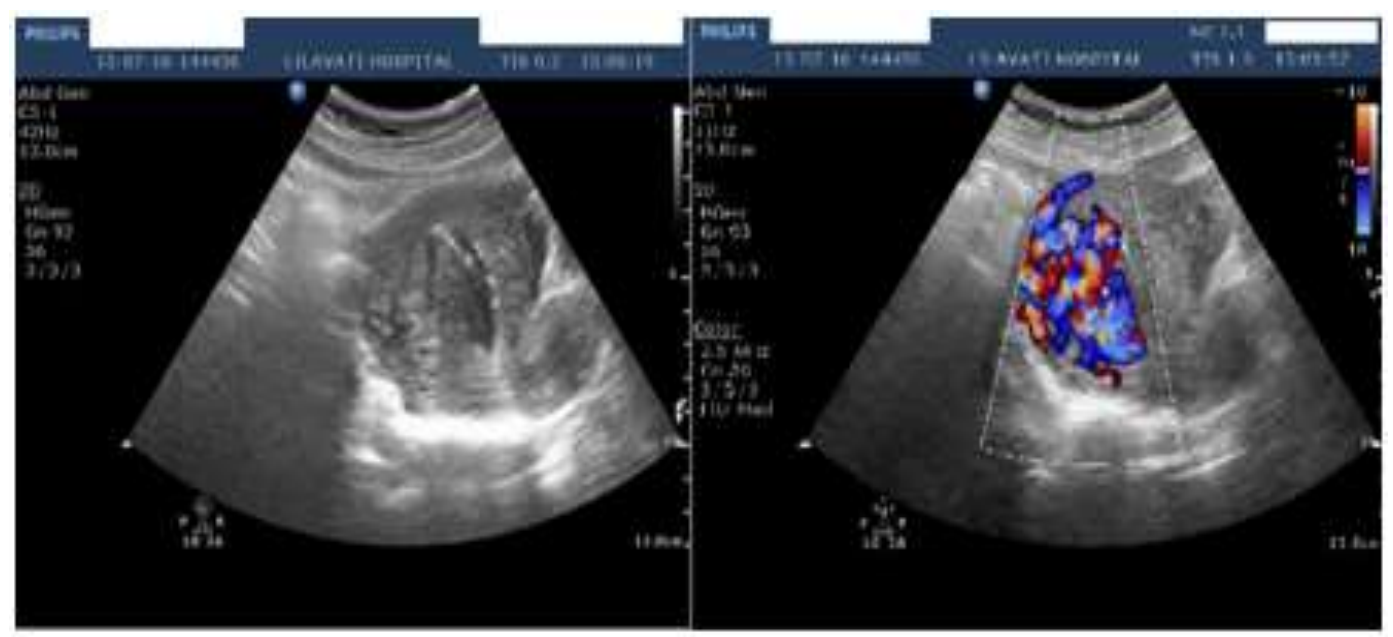

Figure 2: USG-pelvis revealed $8.8 \mathrm{~cm} \times 7.5 \mathrm{~cm} \times 7.5 \mathrm{~cm}$ bulky uterus the posterior myometrium markedly enlarged and heterogeneous with increased vascularity on Doppler. Doppler showed PSV of $121 \mathrm{~cm} / \mathrm{s} \&$ RI of 0.36 i.e., high velocity, low resistance flow, ET-14mm in lower uterine segment. Reproduced from: [16] Shintre H S, Coelho K S. Managing Uterine Arteriovenous Malformation (AVM) Is Like Dealing with Raging Wildfire Awaiting A Spark: Better Be Extremely Cautious \& Be Ready With Counter Measures Like Uterine Artery Embolization (UAE). Obstet. Gynecol. Int. J. 2017; 6(1): 00195 DOI: 10.15406/ogij:2017.06.00195

https://medcraveonline.com/OGIJ/managing-uterine-arteriovenous-malformation-avm-is-like-dealing-with-raging-wildfire-awaiting-a-spark-betterbe-extremely-cautious-amp-be-ready-with-countermeasures-like-uterine-artery-embolization-uae.html under copy right @2017 Shintre, et al. This is an open access article distributed under the terms of the, which permits unrestricted use, distribution, and build upon your work non-commercially

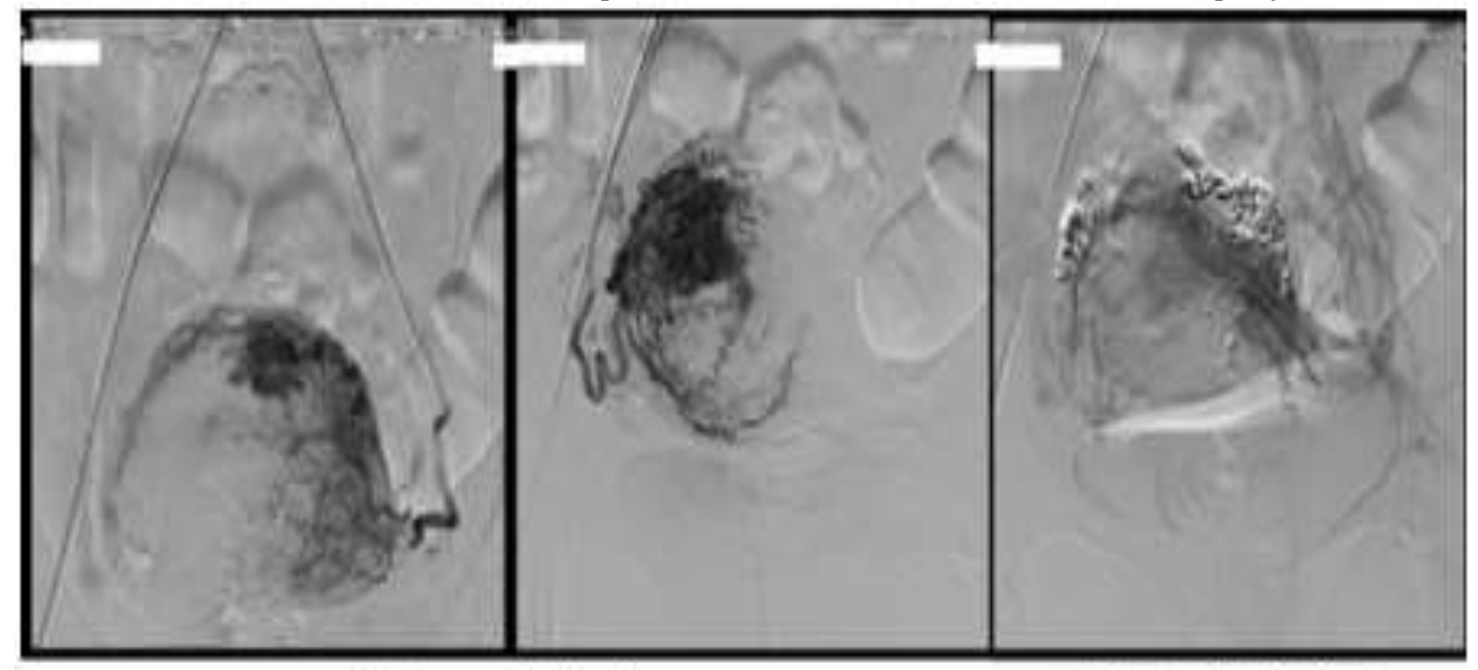

\section{Before embolisation}

\section{After embolisation}

Figure 3: Digital subtraction angiography (DSA) showing bilateral hypertrophy of uterine arteries that feed a tortuous, hypertrophic arterial mass with capillary lakes and post uterine AVM embolization film demonstrating successful embolization of the feeding vessels of AVM with the help of $N$ butyl cyanoacrylate (glue). Reproduced from: [16] Shintre H S, Coelho K S. Managing Uterine Arteriovenous Malformation (AVM) Is Like Dealing

With Raging Wildfire Awaiting A Spark: Better Be Extremely Cautious \& Be Ready With Counter Measures Like Uterine Artery Embolization (UAE). Obstet. Gynecol. Int. J. 2017; 6(1): 00195 DOI: 10.15406/ogij:2017.06.00195

https://medcraveonline.com/OGIJ/managing-uterine-arteriovenous-malformation-avm-is-like-dealing-with-raging-wildfire-awaiting-a-spark-betterbe-extremely-cautious-amp-be-ready-with-countermeasures-like-uterine-artery-embolization-uae.html under copy right @2017 Shintre, et al. This is an open access article distributed under the terms of the, which permits unrestricted use, distribution, and build upon your work non-commercially 


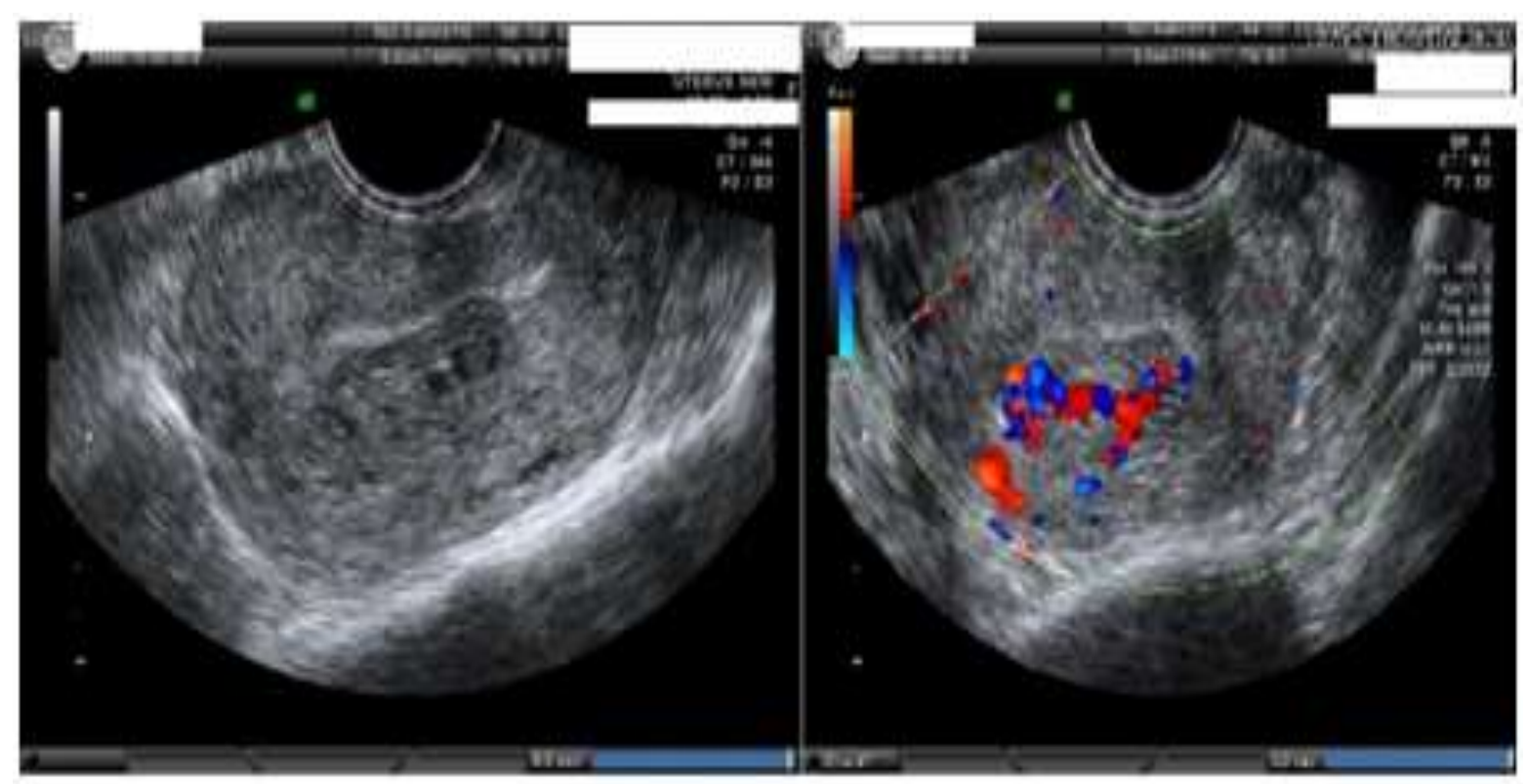

Figure 4: After 6 weeks of uterine AVM embolization, USG-pelvis revealed diminished size of AVM $(1.3 \mathrm{~cm} \times 1.7 \mathrm{~cm} \times 1,5 \mathrm{~cm})$ with diminished vascularity on Doppler. Reproduced from: [16] Shintre H S, Coelho K S. Managing Uterine Arteriovenous Malformation (AVM) Is Like Dealing With Raging Wildfire Awaiting A Spark: Better Be Extremely Cautious \& Be Ready With Counter Measures Like Uterine Artery Embolization (UAE). Obstet. Gynecol. Int. J. 2017; 6(1):00195 DOI: 10.15406/ogij:2017.06.00195

https://medcraveonline.com/OGIJ/managing-uterine-arteriovenous-malformation-avm-is-like-dealing-with-raging-wildfire-awaiting-a-spark-betterbe-extremely-cautious-amp-be-ready-with-countermeasures-like-uterine-artery-embolization-uae.html under copy right (C2017 Shintre, et al. This is an open access article distributed under the terms of the, which permits unrestricted use, distribution, and build upon your work non-commercially

Karadag et al. [1] reported a 35-year-old lady Gravida 2 Para 1, abortion 1, who had undergone dilatation and curettage (D/C) at 9 weeks in view of missed abortion 2 weeks earlier in a different establishment (see figure 1). She did undergo repeated dilatation and curettage (D\&C) procedure during her follow-up visit one week pursuant her initial intervention in another establishment with a suspected haematoma; nevertheless, the procedure was discontinued as a result of haemorrhage and she was referred to the tertiary hospital establishment of the authors. No obvious bleeding was found from her vagina. She had trans-vaginal ultrasound scan which demonstrated a $6.0 \mathrm{~cm}$ x $6.0 \mathrm{~cm} \times 5.6 \mathrm{~cm}=103 \mathrm{~cm} 3$ hyperechogenic and heterogenous mass lesion which was localized within the anterior wall of her uterus and which had extended laterally on the left side. There was evidence of minimal collection of fluid within her endometrial cavity. Her haemoglobin was 112 grams per decilitre, her HCC was $35.1 \%$, her B-HCG was 3518 m IU/ML. Her adnexa on both sides did appear normal. She had Doppler ultrasound scan which demonstrated prominent vascular signals (see figure 5). She was admitted to hospital based upon a diagnosis of arterio-venous malformation of her uterus. She underwent bilateral uterine artery embolization of a mixture of Histoacryl and Lipiodol. The pre as well as the post- embolization images of the procedure are illustrated in figure 6 . There was no complication associated with the procedure. She was discharged 2 days pursuant to her embolization procedure and her B-HCG level had decreased to $1766 \mathrm{M}$ IU/ML. She had follow-up Colour Doppler ultrasound scan of pelvis one month pursuant to her discharge home which did not demonstrate any blood flow and the lesion did measure 6.1 $\mathrm{cm} \times 4.6 \mathrm{~cm} \times 5.2 \mathrm{~cm}\left(77 \mathrm{~cm}^{3}\right)$ and with evidence of shrinkage (see figure 7) and her B-HCG level was less than 0.5 M IU/ML. A lesson that has been learnt from this case report is that AVMU can be safely treated by means of uterine artery embolization (UAE) which tends to be associated with a minimal morbidity and short period of hospital admission. 


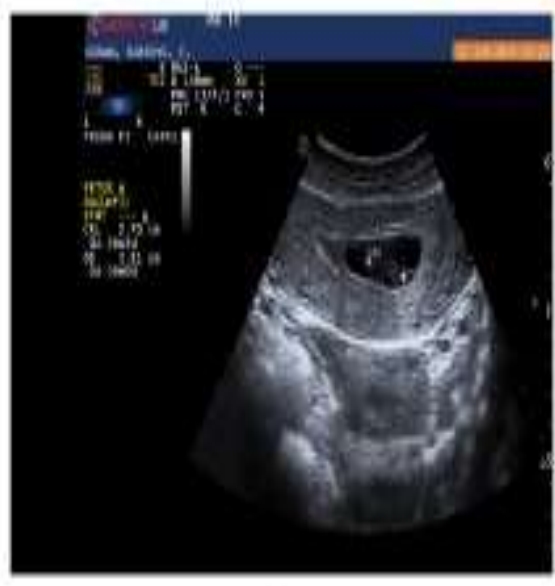

(a)

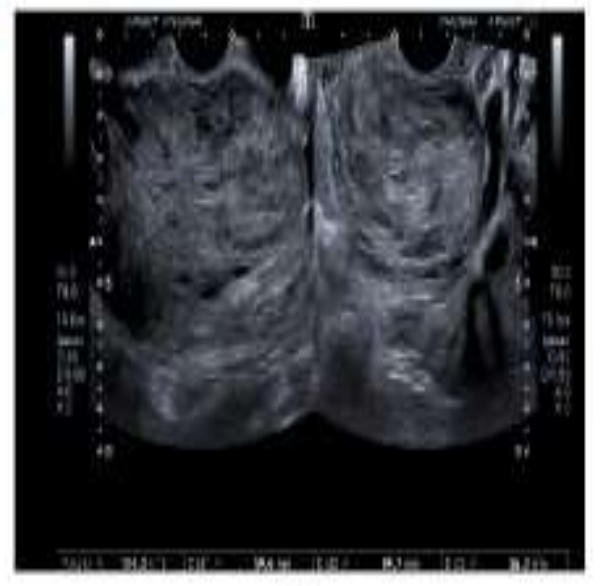

(b)

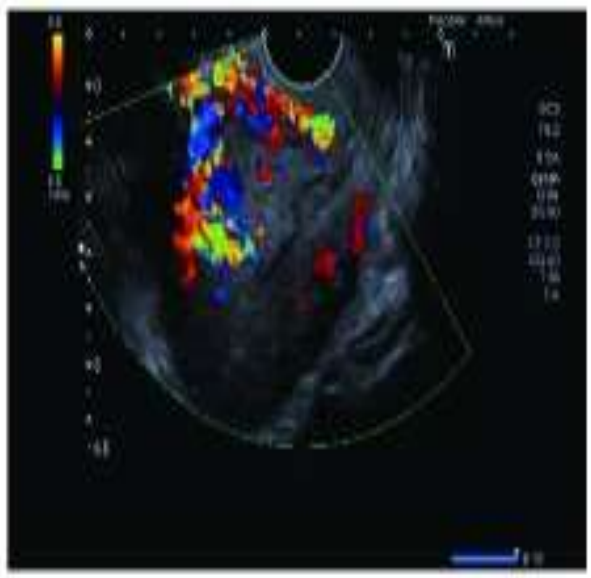

(c)

Figure 5:

(a) Ultrasound image just before D/C shows 9-week foetus with no cardiac activity and there is no sign of uterine AVM. (b) Sagittal endo-vaginal image of the uterus shows $60 \times 60 \times 56 \mathrm{~mm}(103 \mathrm{~cm} 3)$ hyper-echogenic and heterogeneous mass lesion located in the anterior wall of the uterus and extending laterally at the left. (c) Colour Doppler image shows multiple tortuous vessels. Reproduced from: [1] Karadag B, Erol O, Ozdemir O, Uysal A, Alparslan AS, Gurses C, Koroglu M. Successful Treatment of Uterine Arteriovenous Malformation due to Uterine Trauma. Case Rep Obstet Gynecol. 2016;2016:1890650. doi: 10.1155/2016/1890650. Epub 2016 Sep 6. PMID: 27699074; PMCID: PMC5028872. https://pubmed.ncbi.nlm.nih.gov/27699074/ ] under the Creative Commons Attribution License.

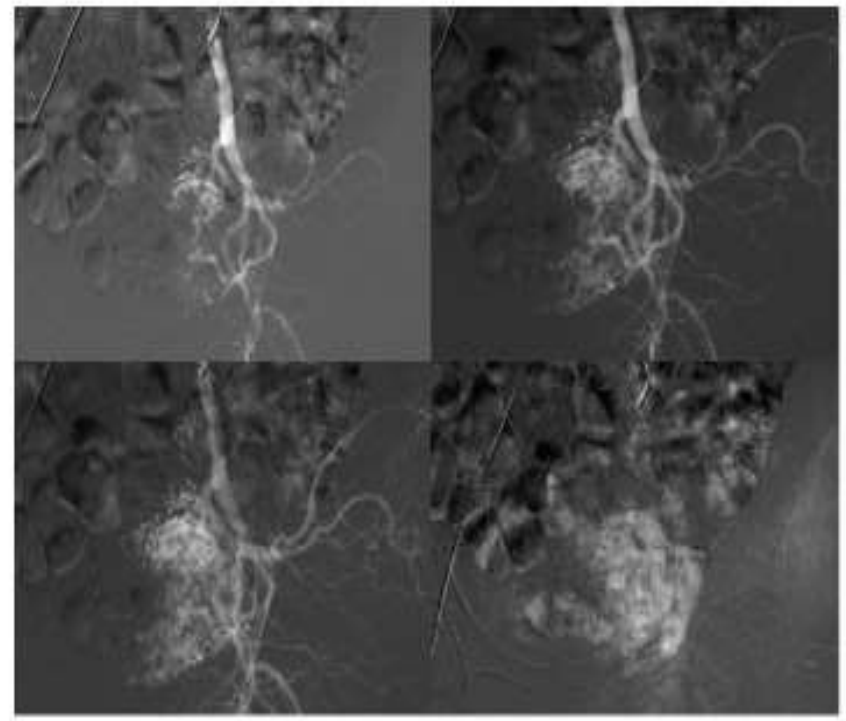

(a)

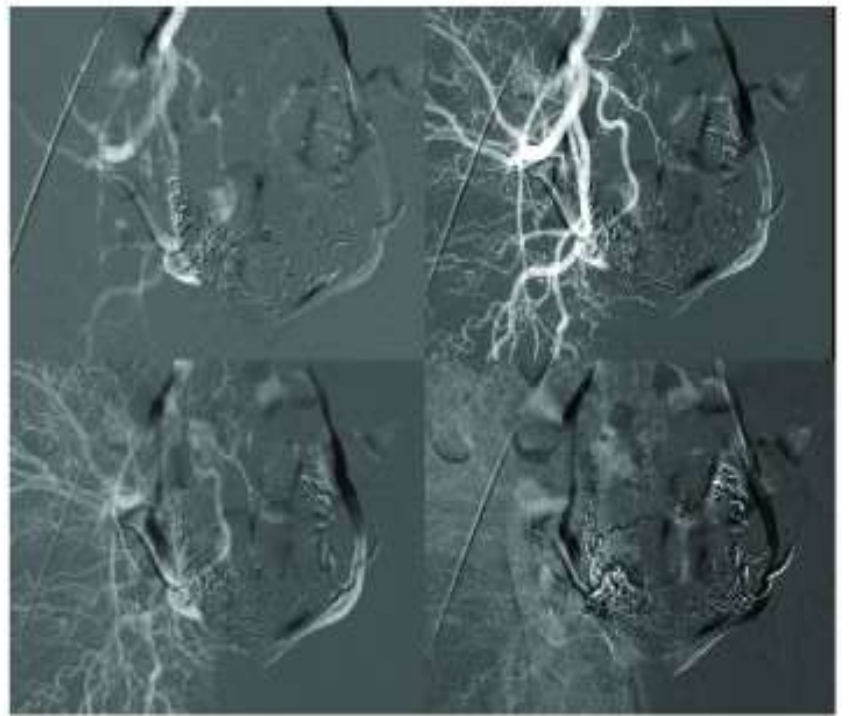

(b)

Figure 6:

Right internal iliac uterine artery angiography showing opacification of a slightly enlarged right uterine artery and hyper-vascular mass in the uterus. (b) Post-embolization angiographic image. Reproduced from: [1] Karadag B, Erol O, Ozdemir O, Uysal A, Alparslan AS, Gurses C, Koroglu

M. Successful Treatment of Uterine Arteriovenous Malformation due to Uterine Trauma. Case Rep Obstet Gynecol. 2016;2016:1890650. doi:

10.1155/2016/1890650. Epub 2016 Sep 6. PMID: 27699074; PMCID: PMC5028872. https://pubmed.ncbi.nlm.nih.gov/27699074/ ] under the Creative Commons Attribution License. 


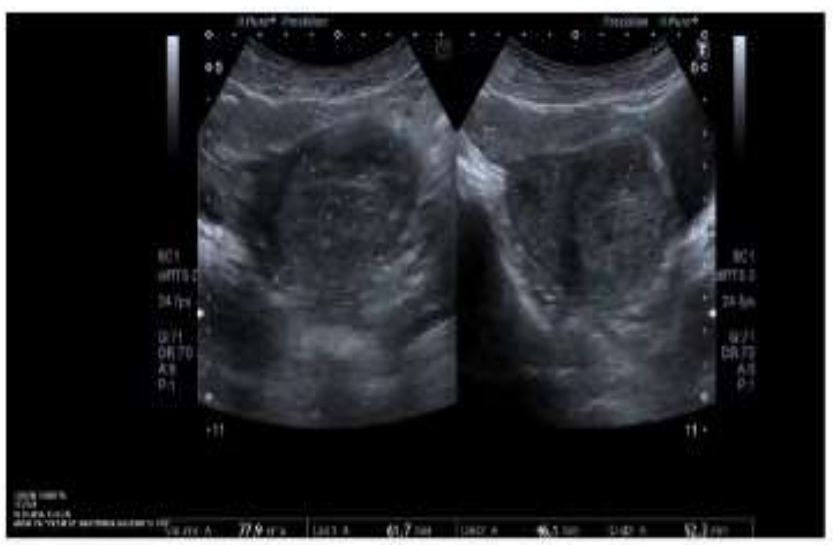

(a)

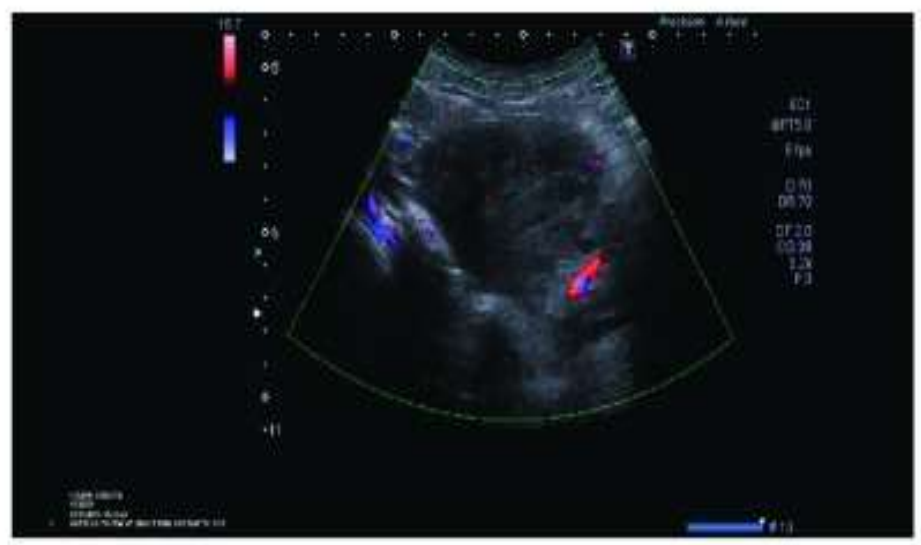

(b)

Figure 7:

A repeat trans-vaginal ultrasound and Colour Doppler done two months later; (a) the lesion was measuring $61 \times 46 \times 52 \mathrm{~mm}(77 \mathrm{~cm} 3)$ and (b) revealed no blood flow. Reproduced from: [1] Karadag B, Erol O, Ozdemir O, Uysal A, Alparslan AS, Gurses C, Koroglu M. Successful Treatment of Uterine Arteriovenous Malformation due to Uterine Trauma. Case Rep Obstet Gynecol. 2016;2016:1890650. doi: 10.1155/2016/1890650. Epub 2016 Sep 6. PMID: 27699074; PMCID: PMC5028872. https://pubmed.ncbi.nlm.nih.gov/27699074/ ] under the Creative Commons Attribution License.

Hashim and Nawawi [18] iterated that AVMU is an uncommon condition with less than 100 cases reported in the literature by 2013 and that AVMU is potentially a life-threatening condition. Hashim and Nawawi [18] reported a 33-year-old lady who had manifested with secondary postpartum haemorrhage. She had trans-abdominal ultrasound scan (US) of her pelvis which demonstrated increased vascularity with multidirectional flow of the uterus as well as a prominent vessel, which was located upon the left lateral wall of the uterus. There were multiple feeding arteries which were mainly from her left uterine artery with smaller feeding arteries from the right. An early draining vein was also visualized. She was also found to have retained products of conception which had complicated her diagnosis. She had uterine artery angiography which confirmed AVMU within the fundal region of her uterus with an early draining vein. Embolization of the AVMU was successfully undertaken. Her vaginal bleeding decreased post-embolization and she recovered well, and she was discharged home.

Sridhar and Vogelzang [19] iterated that less than 150 cases of AVMUs of the pelvis and uterus had been reported by 2018, but in their opinion, the true incidence of AVMU could be higher. They also stated that a prospective study of 959 patients did find sonography feature evident AVMUs in $5.2 \%$ of women after dilatation and curettage (D\&C) and in $0.22 \%$ of women pursuant to delivery of their babies; nevertheless, only one case that amounted to $0.1 \%$ of the AVMUs within the study population was deemed to be clinically significant.

Yawaza et al.[20] reported their prospective evaluation of the incidence of vascular malformations of the uterus that develop following abortion or delivery. [20] They pointed out that Pelvic AMS and AVMUs are distinct entities that have different aetiologies, manifestations, as well as management.

Katimada et al. [21] made the ensuing key point summations related to arteriovenous malformations of the uterus (AVMUs):

- The incidence as well as the prevalence of arteriovenous malformations of the uterus (AVMUs) is difficult to ascertain in view of the fact that bleeding which is caused by AVMUs does respond to medical management as well as several of these AVMUs could go unnoticed.
- Less than 100 AVMUs had been reported in the literature; nevertheless, the increasing utilization of radiology imaging modalities, in particular ultrasound scan in acute gynaecology conditions would likely emanate in the identification of these AMVUs frequently.

- $\quad$ AVMUs tend to be largely acquired lesions, with pregnancy playing an important role with regard to the pathogenesis of these AVMUs.

- The commonest clinical manifestation of AVMU is abnormal uterine bleeding, which could often be episodic, torrential, as well as it can emanate in significant anaemia or shock.

- The undertaking of hysterectomy does remain the most definitive treatment of AVMU; nevertheless, modern management of AVMUs does vary from medical treatment which entails utilization of hormonal treatment through minimally invasive embolization of the uterine artery to the more definitive surgical hysterectomy.

- Because of the rarity of AVMUs clinicians need to be aware of the existence of AVMUs and they need to understand the risk factors as well as clinical manifestations of women who should be suspected of having AVMUs.

- It is important to learn about the various conservative treatment options that are utilized for the management of AVMUs.

Ore et al. [22] reported a 30-year-old gravida 3 Para 2012 (G3P2012), lady who initially manifested with heavy vaginal bleeding. She stated that she did wake up in the middle of the night and she found that she was in a pool of blood. Her menstrual period had commenced the day preceding her presentation. She had a past medical history of having had severe bleeding from her genital tract which had necessitated multiple hospital admissions. She had presented 6 months preceding her current manifestation to another medical establishment with acute abdomen and she was rushed into theatre for exploratory laparotomy which had demonstrated hemoperitoneum. The source of bleeding was considered to be from the fundus of her uterus which was oversewn, and she was transfused with 5 units of blood. The exact cause of the haemorrhage was not 
ascertained at that time, and she was discharged in a state of fitness and wellness. Three months subsequently, she re-presented to a different hospital, with profuse bleeding from her vagina. She was treated by means of hormonal treatment and transfusion with 3 units of blood, following which she was discharged. Pursuant to few days of her stabilization no definite cause of her vaginal bleeding was found at that time. She denied having ever had any previous instrumentation of her uterus. She did have term deliveries of 2 babies as well as an expectantly managed first trimester loss of a foetus. Her examination during her current presentation demonstrated normal vital signs. A bright red vaginal bleeding was noted during her vaginal examination, with blood flow that was considered to be consistent with heavy menstrual bleeding. She had ultrasound scan of pelvis which demonstrated multiple dilated as well as serpiginous vessels within her para-uterine and arcuate regions that had extended deep into her myometrium, which was considered to be consistent with the diagnosis of arteriovenous malformation of the uterus (AVMU). She was initially treated by means of oral contraceptive pills (OCPs). She underwent computed tomography (CT) angiography of her uterine vasculature which demonstrated enlarged right sided uterine arteries that had brisk drainage into her uterine veins that was consistent with the diagnosis of AVMU. Bilateral uterine artery embolization was undertaken with 900 to 1,200 micron blend microspheres. She was discharged a few days pursuant to her embolization on cyclic low-dose oral contraceptive pills (OCPs). At the time of her discharge, her vaginal bleeding had resolved. At her 1-month post-embolization procedure follow-up assessment, it was noted that her menstrual bleeding was negligible as well as she was strongly getting pregnant again, but she was continued on oral contraceptive pills (OCPs) with a plan for her to be reviewed in 6 months. Four months later, she lost her consciousness that required hospital admission and resuscitation and she was noted to have tachycardia with a heart rate of 109 beats per minute but otherwise her vital signs were normal. She was noted to have a distended abdomen that was associated with rebound tenderness, guarding, as well as a palpable fluid wave. The results of some of her blood tests included: haemoglobin10.7, haematocrit 30.7, platelets 257, INR 1.18, and Beta-HCG negative. She underwent laparotomy which revealed about 3 litres of hemoperitoneum. An area of arterial spray was found along the posterior wall of the fundus of her uterus which was ligated, and it was presumed that the finding was related to AVMU. Hysterectomy was therefore undertaken. Three hours post-operatively the results of her routine blood tests revealed the following: Haemoglobin 5.9, haematocrit 17.2, platelets 108 , INR 2.1. She received 5 units of blood intra-operatively, 2 units of fresh frozen plasma. Gross examination of the surgical specimen demonstrated a uterus that weighed 111 grams and upon sectioning through the body of the uterus multiple ectatic blood vessels were seen that measured up to $0.4 \mathrm{~cm}$ in diameter that were primarily localized within the myometrium and which focally did approach the serosa surface of the uterus. The vessels did appear to be a mixture of muscular arteries with fibro-myxoid changes as well as thick-walled veins upon application of elastic stain. Examination of the specimen demonstrated discontinuous internal elastic lamina. CD31 staining of the specimen did reveal loss of normal endothelial lining, which was considered might have been associated with the previous embolization. She did recover well post-operatively. Prior to her discharge, she had CT angiogram of the lungs, and brain which did exclude any AVM within the lungs, and the brain. She subsequently discharged home. Some of the lessons that can be learnt from this case report include:

- When embolization is undertaken that has stopped bleeding from a large AVMU, there could still be subsequent bleeding which at times could be severe, therefore careful follow-up assessment and further embolization may be required to prevent subsequent severe bleeding that may require the undertaking of hysterectomy.

- It is important to review individuals who have undergone embolization for AVMU to ascertain those could possibly bleed in the future.

- Even though embolization does prove to be effective treatment for many cases of AVMU, some individuals who have AVMU would inevitably require a definitive treatment by means of hysterectomy.

Ore et al. [22] made the following summations related to AVMUs:

- $\quad$ AVMU does primarily manifest in females whose ages tend to range between 20 years and 40 years.

- There are two types of AVMU that include congenial AVMU and acquired AVMU.

- It has been iterated that abnormal embryological differentiation of primitive vascular structures has been the conjectured aetiology of AVM. Abnormal embryological differentiation of primitive structures has been stipulated to lead to inadequate capillary formation and the resultant arteriovenous fistula connections [23]

- It has been iterated that congenital AVMU could extend beyond the confines of the uterus into the pelvis and it does more commonly involve multiple vascular connections. [23]

- Acquired AVMU does involve an abnormal arteriovenous connection which does form following a disruption as well as a defective healing of the vasculature of the uterus. This acquired AVM abnormal connection could form pursuant to a surgical procedure for examples curettage of the endometrium (D\&C), or caesarean section. It has been iterated that acquired AVMU tends to be more commonly encountered pursuant to or associated with some conditions including endometritis, pregnancy, gestational trophoblastic disease, or endometriosis [5] [23]

- With regard to their reported case, they had suspected that the case was that of congenital arteriovenous malformation (AVM) after taking into consideration the extensive nature of the AVMU as well as lack of prior risk factors for acquired AVMU. Khan et al. [24] reported a 30-year-old G1P0010 lady wo had manifested with a 6 days history of abnormal bleeding from her uterus. Three months preceding her presentation, she had undergone a therapeutic abortion which was ensued by dilatation and curettage (D\&C) for retained products of conception. Since then, she realised that she had developed a new onset of menorrhagia, which on the day of her manifestation had become persistent and which had become associated with severe pain, weakness, as well as dizziness. Upon her examination, she was observed to be hypotensive, and she had tachycardia. She had marked tenderness within her supa-pubic region. Her examination was otherwise normal. Some of the results of her laboratory blood tests included: haemoglobin 9.2 grams per decilitre, haematocrit $27.5 \%$ and negative serum Beta Human Chorionic Gonadotrophin (B-HCG). She trans-vaginal ultrasound scan which showed a $3.9 \mathrm{~cm}$ x $2.7 \mathrm{~cm}$ x $1.8 \mathrm{~cm}$ sized an-echogenic cystic spaces within the posterior wall of the fundus of her uterus (see figure 8). She had Doppler ultrasound scanning which revealed marked vascularity within her uterus (see figure 9). She had magnetic resonance imaging (MRI) scan of pelvis which showed a contrast-opacified structure within structure within the wall of her myometrium. Focal serpiginous flow voids were also demonstrated within the posterior-superior myometrium with extension to the 
canal of her myometrium (see figure 10). The features of the radiology were interpreted to be consistent with the diagnosis of arteriovenous malformation of the uterus (AVMU). She had uterine angiogram which confirmed features of arteriovenous malformation of the uterus (AVMU) within the posterior-superior wall of the uterus (see figure 11). The angiogram did demonstrate presence of multiple feeding arteries which had arisen mainly from the left with smaller arteries from the right side. Embolization of both uterine arteries was undertaken with utilization of Gelfoam (Pfizer, New York) pledgets to near stasis. She had a post-embolization arteriogram which demonstrated complete embolization of the AVMU as well as evidence of slow flow of contrast in both uterine arteries. No immediate complications emanated. Her vaginal bleeding stopped. She was discharged home on her $3^{\text {rd }}$ day postembolization. During her follow-up assessment, 3 weeks pursuant to her embolization there was no evidence of recurrence of abnormal uterine bleeding. The lesson that has been learnt from this case report is that embolization of the uterine artery supplying the AVMU is an effective minimally invasion option of treating AVMUs.

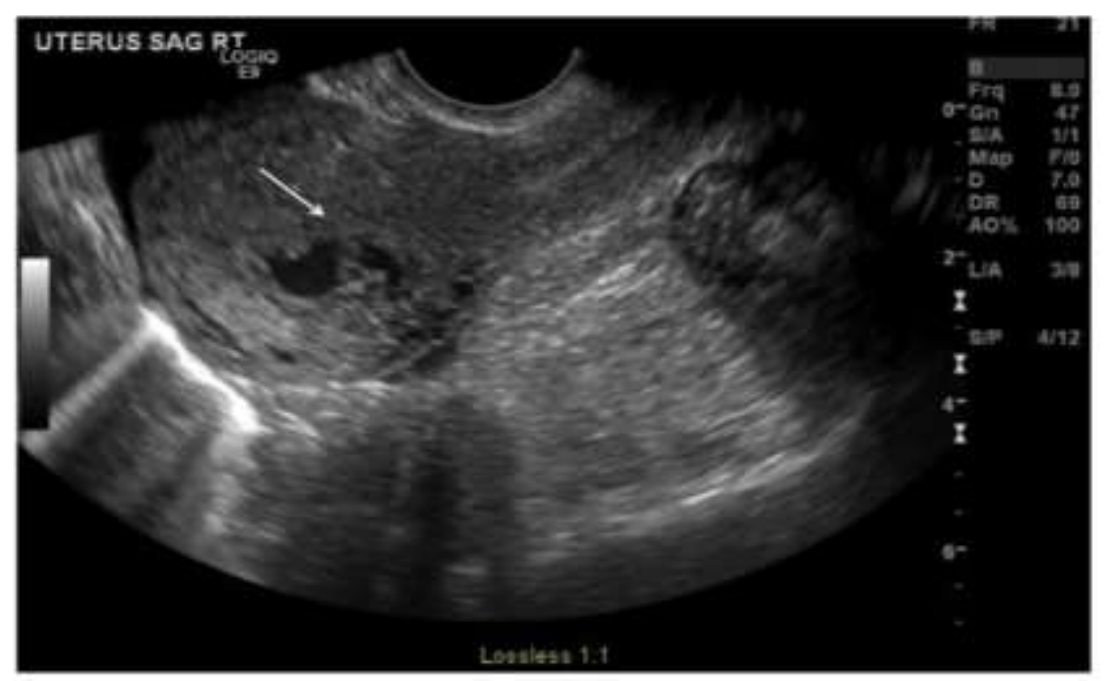

Figure 8:

Trans vaginal ultrasound of the uterus showing a hypoechoic lesion in the body of the uterus. Reproduced from: [24] Khan S, Saud S, Khan I, Achakzai B. Acquired Uterine Arteriovenous Malformation Following Dilatation and Curettage Treated with Bilateral Uterine Artery Embolization: A Case Report. Cureus. 2019 Mar 13;11(3):e4250. doi: 10.7759/cureus.4250. PMID: 31131173; PMCID: PMC6516630.

https://pubmed.ncbi.nlm.nih.gov/31131173/ under Copyright ( 1 2019, Khan et al. This is an open access article distributed under the terms of the Creative Commons Attribution License, which permits unrestricted use, distribution, and reproduction in any medium, provided the original author and source are credited.

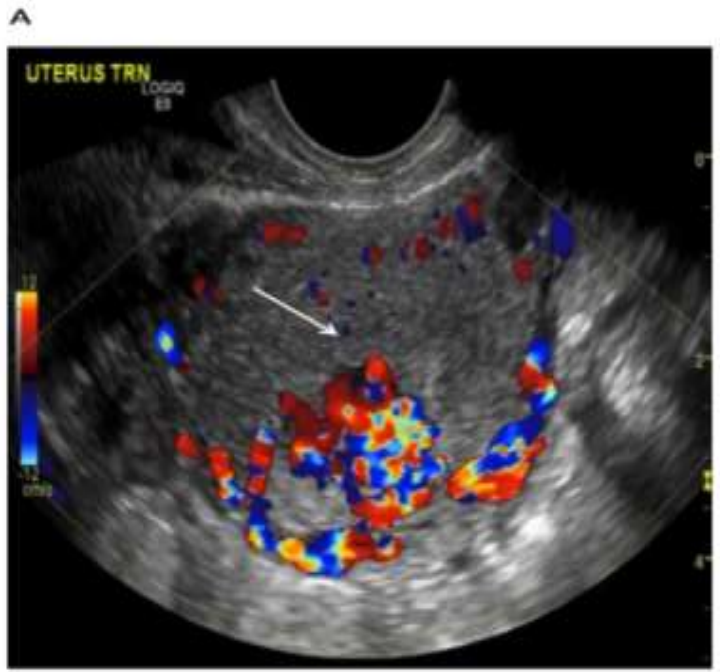

\section{B}

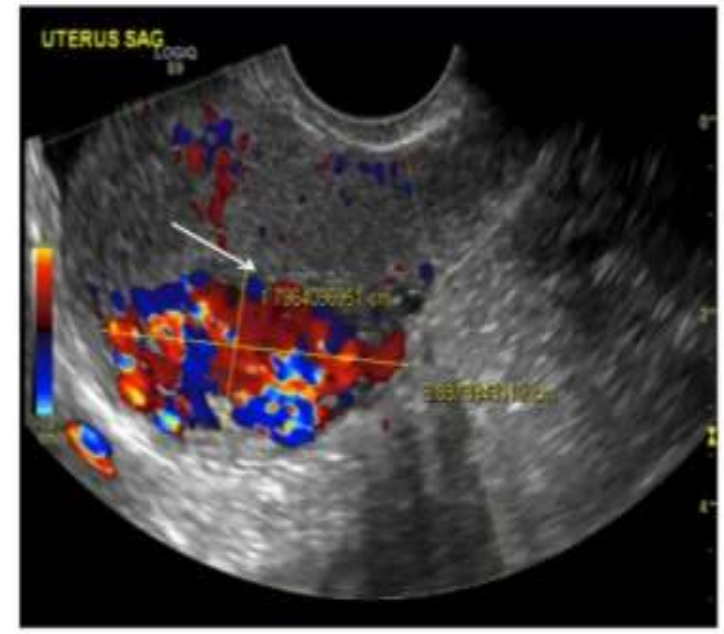

Figure 9:

Trans vaginal ultrasound of the uterus with Doppler revealing a hyper-vascular lesion: (A) transverse view (B) sagittal view. Reproduced from: [24] Khan S, Saud S, Khan I, Achakzai B. Acquired Uterine Arteriovenous Malformation Following Dilatation and Curettage Treated with Bilateral

Uterine Artery Embolization: A Case Report. Cureus. 2019 Mar 13;11(3):e4250. doi: 10.7759/cureus.4250. PMID: 31131173; PMCID:

PMC6516630. https://pubmed.ncbi.nlm.nih.gov/31131173/ under Copyright @ 2019, Khan et al. This is an open access article distributed under the terms of the Creative Commons Attribution License, which permits unrestricted use, distribution, and reproduction in any medium, provided the original author and source are credited. 
A

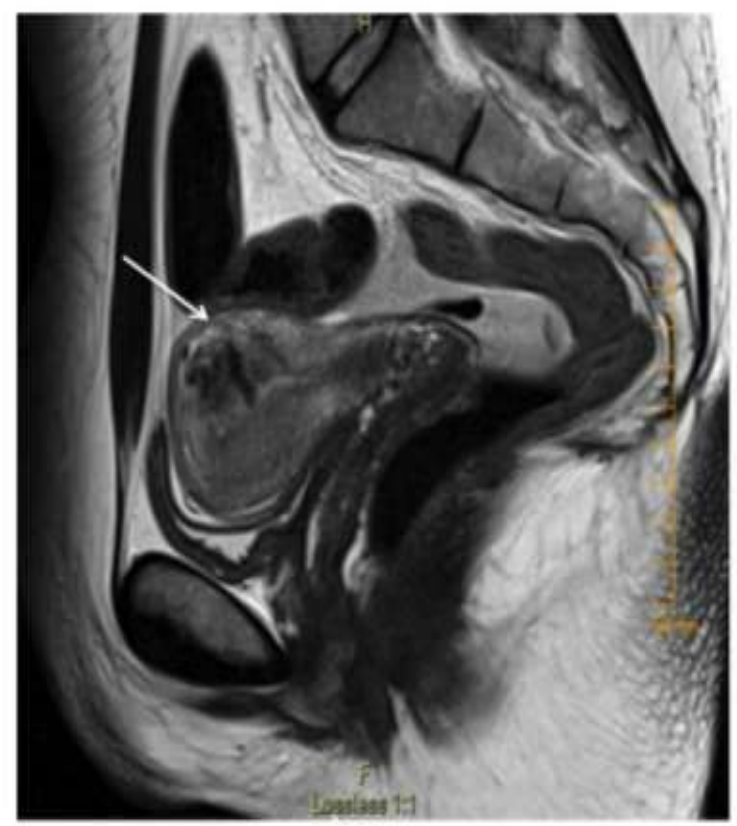

B

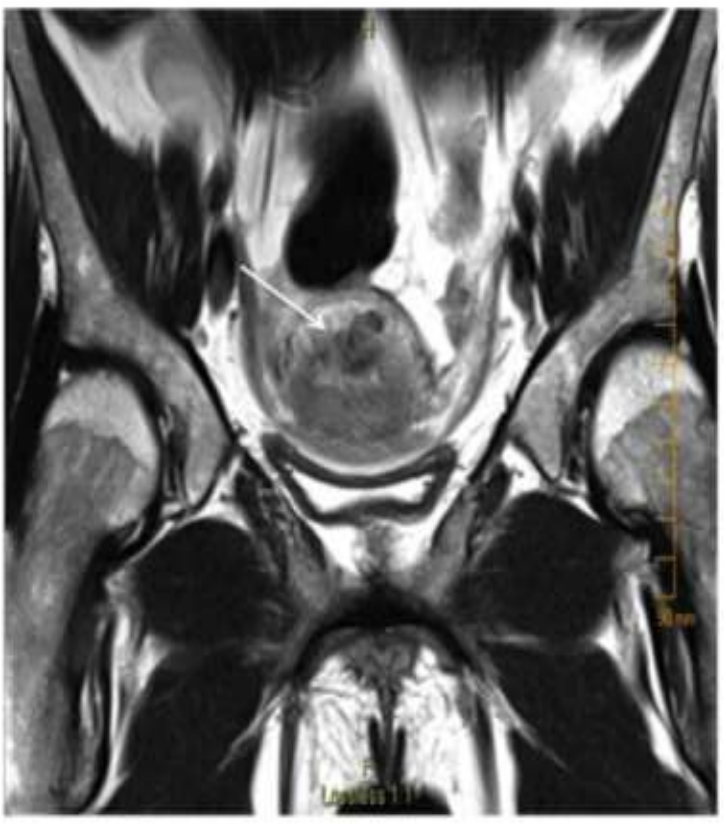

Figure 10: T2-weighted pelvic magnetic resonance imaging (MRI) revealing a hypo-intense T2 lesion within the posterosuperior wall of the myometrium: (A) sagittal view (B) axial view. Reproduced from: [24] Khan S, Saud S, Khan I, Achakzai B. Acquired Uterine Arteriovenous Malformation Following Dilatation and Curettage Treated with Bilateral Uterine Artery Embolization: A Case Report. Cureus. 2019 Mar 13;11(3):e4250. doi: 10.7759/cureus.4250. PMID: 31131173; PMCID: PMC6516630. https://pubmed.ncbi.nlm.nih.gov/31131173/ under Copyright (c) 2019, Khan et al. This is an open access article distributed under the terms of the Creative Commons Attribution License, which permits unrestricted use, distribution, and reproduction in any medium, provided the original author and source are credited.

A

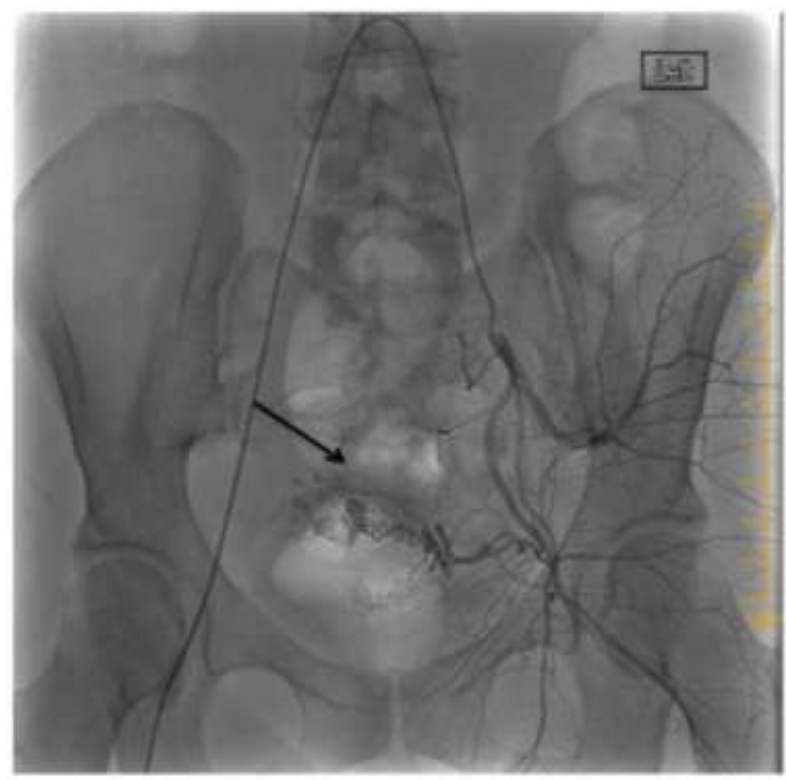

B

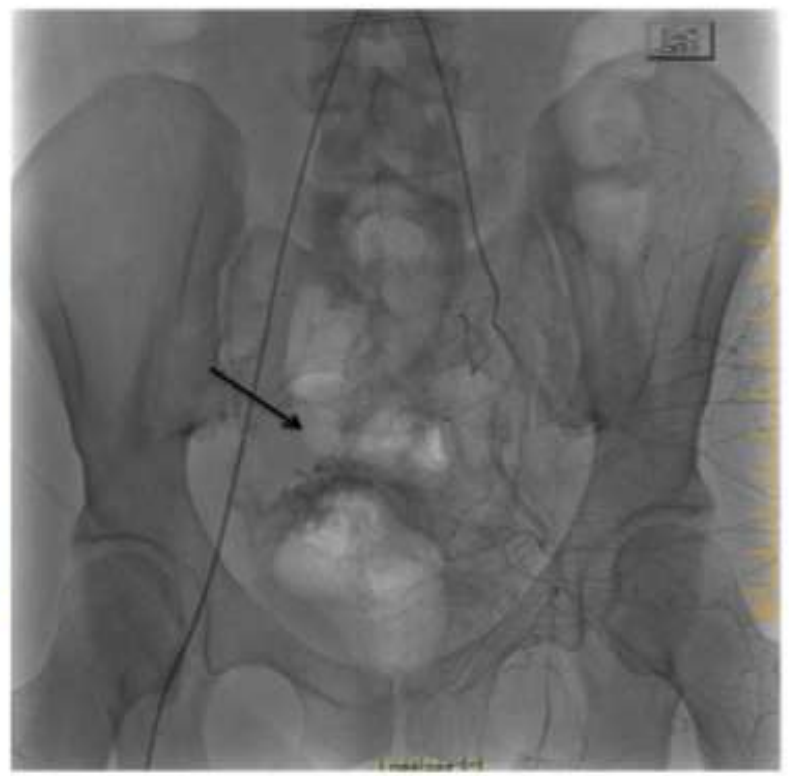

Figure 11: Left internal iliac artery angiogram revealing a hyper-vascular lesion within the uterine artery distribution with early venous filling during the late arterial phase: (A) early arterial phase (B) late arterial phase. Reproduced from: [24] Khan S, Saud S, Khan I, Achakzai B. Acquired Uterine Arteriovenous Malformation Following Dilatation and Curettage Treated with Bilateral Uterine Artery Embolization: A Case Report. Cureus. 2019 Mar 13;11(3):e4250. doi: 10.7759/cureus.4250. PMID: 31131173; PMCID: PMC6516630.

https://pubmed.ncbi.nlm.nih.gov/31131173/ under Copyright ( 12019 , Khan et al. This is an open access article distributed under the terms of the Creative Commons Attribution License, which permits unrestricted use, distribution, and reproduction in any medium, provided the original author and source are credited. 
Jacques et al. [25] reported a 27-year-old year old null gravid lady, who was on warfarin anticoagulation in view of her having a mechanical tricuspid valve and underlying congenital heart disease, who manifested with sudden onset of profuse vaginal bleeding despite being on continuous oral contraceptive pills. She had been admitted on three separate occasions over a period of 3 months for the management of menorrhagia and overall, she had been transfused with 25 units of blood. During her initial assessment, she received high-dose intravenous oestrogen successfully and she was discharged home on oral contraceptive pill. Her vaginal bleeding recommenced many weeks subsequently and upon her admission she had examination of her pelvis which demonstrated a bluish mass at the apex of her vagina which was suspected to be an arteriovenous malformation (AVM). In view of the bleeding with utilization of hormones as well as a question of a possible mass within her vagina on examination, she had an MRI scan of pelvis which demonstrated blood products at varying stages that had expanded the endometrial cavity without any definite cause identified as well as no arteriovenous malformation (AVM) was identified (see figure 12). She underwent dilatation and curettage (D\&C) as well as placement of levonorgestrel intra-uterine device. Pathology examination of the curetting demonstrated benign endometrium that had progestin effect. She was discharged home and she was well for one week until her intra-uterine device (IUD) was expelled and she re-commenced bleeding again from her vagina for which she was initially managed by means of placement of an etonogestrel implant. She was re-admitted one week later due to her profuse bleeding from her vagina that required blood transfusion. An attempt was made to treat her with leuprolide which did not produce any successful effect. She was on warfarin treatment, which was reversed, and she underwent laparoscopic hysterectomy. There was no suspicion of AVU during the operation. Pathology examination of the surgical specimen did not demonstrate any abnormalities within her uterus, cervix, and fallopian tubes. She was well for 4 weeks after her operation but she suddenly re-manifested with bleeding from her vagina that required utilization of wall suction for visualization of her vagina and cervix and the bleeding was observed at the right side of her vaginal cuff. Her vagina was packed with gauze and she had CT angiogram which demonstrated active arterial bleeding within the right side of the apex of her vagina which was suggestive of an AVM (see figure 13). She was transfused with 2 units of packed red blood cells and prothrombin complex concentrate (PCC) was used to reverse her anti-coagulation. She had angiogram which revealed active extravasation from her right uterine artery with an artery to venous fistula (see figure 14). Two coils had to be placed proximal to the part of the uterine vessel which had vaginal branches, and this emanated in successful obliteration of the AVMU as well as cessation of her vaginal bleeding. She was recommenced on heparin drip as well as warfarin pursuant to her operation; nevertheless, on the day her INR reached therapeutic range, she re-started having profuse vaginal bleeding again. PCC was utilized to reverse her anticoagulation. She had right internal iliac arteriogram which demonstrated abnormal blush as well arterio-venous fistula (AVF) within the same region as before, near the previously embolized uterine artery (see figure 15). Embolization of her right uterine artery was undertaken with glue. Catheterization of multiple branches of the artery did not demonstrate any extravasation of contrast. She was recommenced on warfarin as well as on heparin drip subsequently until her INR had reached therapeutic range. She was subsequently discharged, and she did not develop any further bleeding from her vagina. At her 6-week post-operative follow-up assessment, her examination demonstrated a well healed, and intact, cuff of her vagina. A lesson that has been learnt from this case report is that if an AVM develops with bleeding following hysterectomy for AVM, selective angiography and embolization could be undertaken to obliterate the AVM and to stop the bleeding

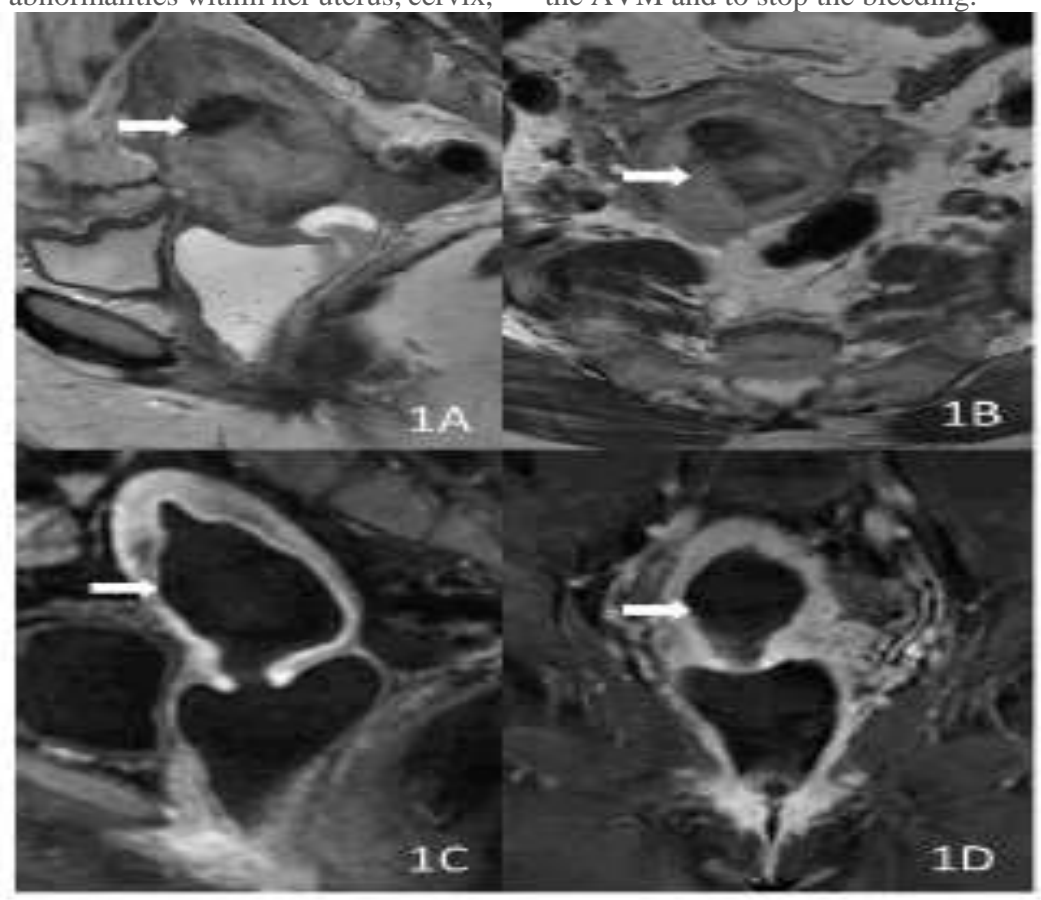

Figure 12: MR image prior to hysterectomy. Images showing: Axial (1A) and Sagittal T2 weighted (8B) and sagittal (8C) and coronal (8D) postcontrast fat saturated T1 weighted MR images showing non-enhancing in homogeneous-intensity fluid in the uterus compatible with acute and subacute blood products (arrows). There is no enhancing mass lesion or evidence of vascular malformation. [25] Jacques L, Lund M, Baruah D. Uterine Arteriovenous Malformation: A Rare Cause Vaginal Hemorrhage after hysterectomy. Gynecology \& Obstetrics Case Report. 2016; 2(2): 1 4. doi:10.21767/2471-8165.1000029 https://gynecology-obstetrics.imedpub.com/uterine-arteriovenous-malformations-a-rare-cause-of-vaginalhemorrhage-after-hysterectomy.pdf https://gynecology-obstetrics.imedpub.com/uterine-arteriovenous-malformations-a-rare-cause-of-vaginalhemorrhage-after-hysterectomy.php?aid=11196 


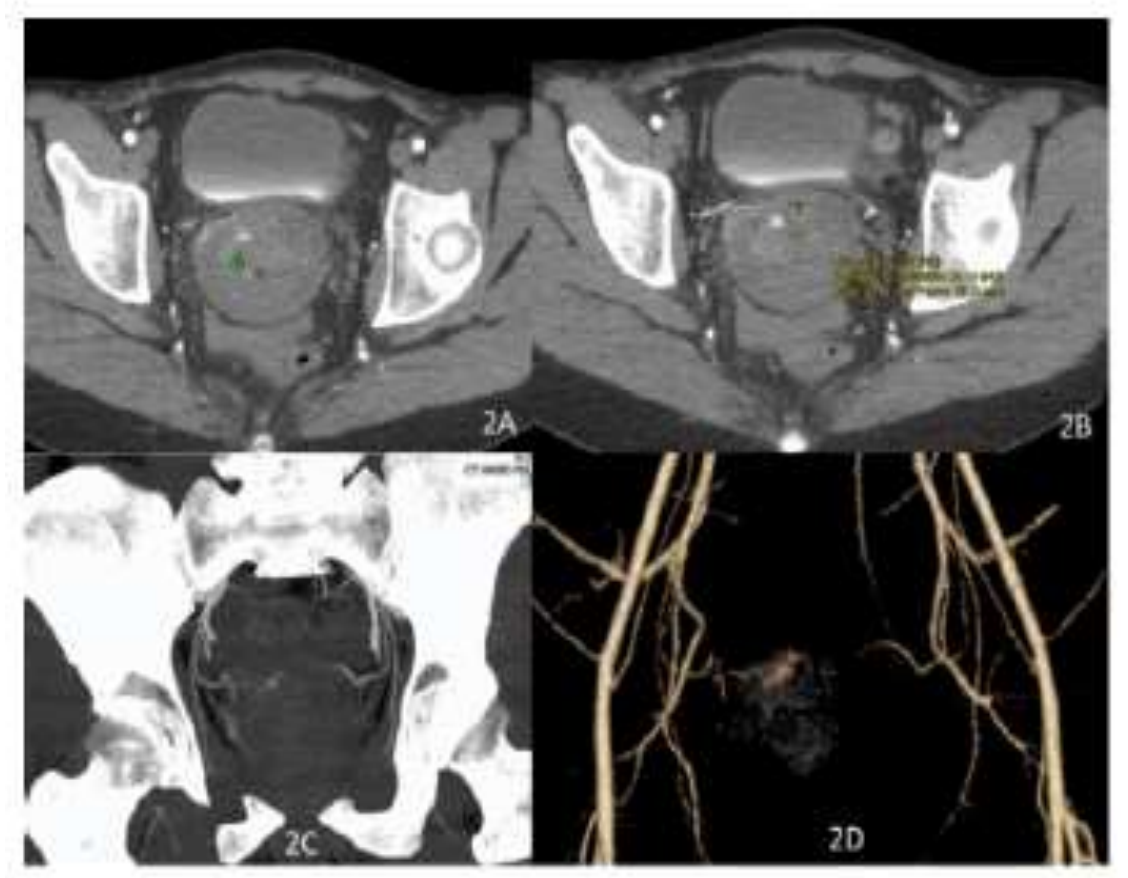

Figure 13:

CT angiography done after hysterectomy prior to the first embolization by interventional radiology. Images showing high density (average Hounsfield Unit 73) acute blood/contrast in the pelvis (9B) with active arterial extravasation (9A). Active arterial extravasation is also seen nicely on maximum intensity projection (9C) and volume rendered (9D) images Reproduced from: [25] Jacques L, Lund M, Baruah D. Uterine Arteriovenous Malformation: A Rare Cause Vaginal Hemorrhage after hysterectomy. Gynecology \& Obstetrics Case Report. 2016; 2(2): 1 - 4. doi:10.21767/24718165.1000029

https://gynecology-obstetrics.imedpub.com/uterine-arteriovenous-malformations-a-rare-cause-of-vaginal-hemorrhage-after-hysterectomy.pdf https://gynecology-obstetrics.imedpub.com/uterine-arteriovenous-malformations-a-rare-cause-of-vaginal-hemorrhage-afterhysterectomy.php?aid=11196

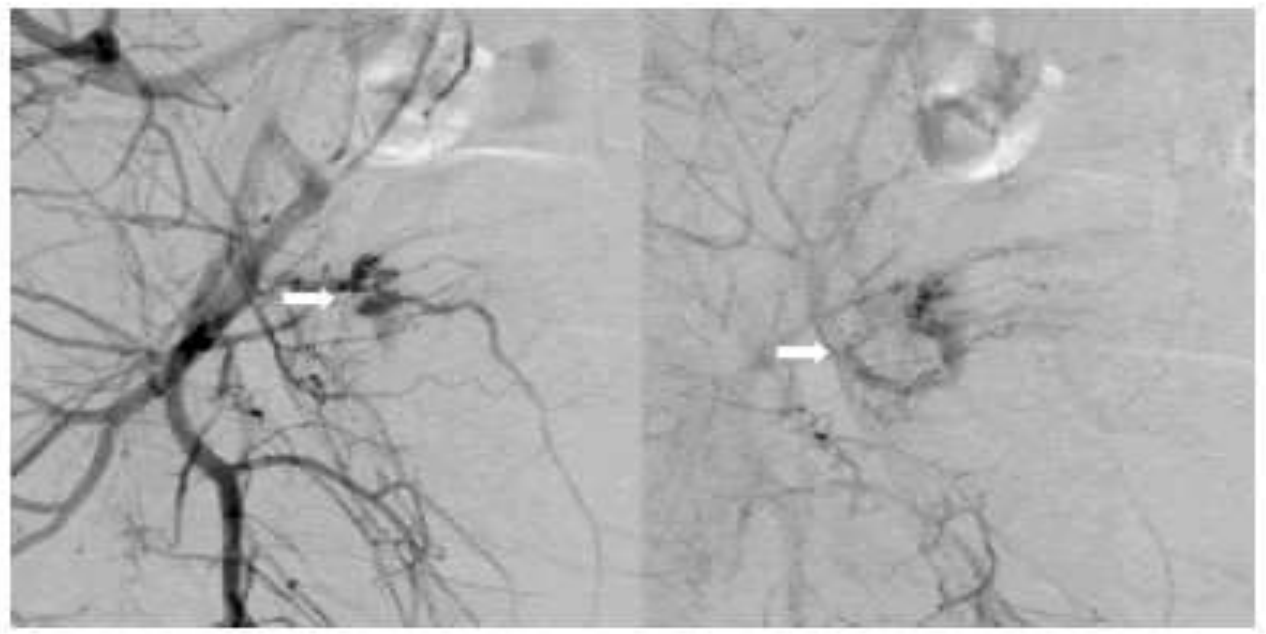

Figure 14

Angiography done at the time of the first uterine artery embolization by interventional radiology. Images showing: (10a). An arteriovenous fistula is noted involving the uterine artery in the catheter angiography (arrows) on right internal iliac artery injection corresponding to the CT angiography abnormality seen on Figure 9, (100b). Arrow showing the uterine artery was after embolization with coils and PVA (polyvinyl alcohol) particles. Reproduced from: [25] Jacques L, Lund M, Baruah D. Uterine Arteriovenous Malformation: A Rare Cause Vaginal Hemorrhage after hysterectomy. Gynecology \& Obstetrics Case Report. 2016; 2(2): 1 -4. doi:10.21767/2471-8165.1000029 https://gynecology-obstetrics.imedpub.com/uterinearteriovenous-malformations-a-rare-cause-of-vaginal-hemorrhage-after-hysterectomy.pdf https://gynecology-obstetrics.imedpub.com/uterinearteriovenous-malformations-a-rare-cause-of-vaginal-hemorrhage-after-hysterectomy.php?aid=11196 


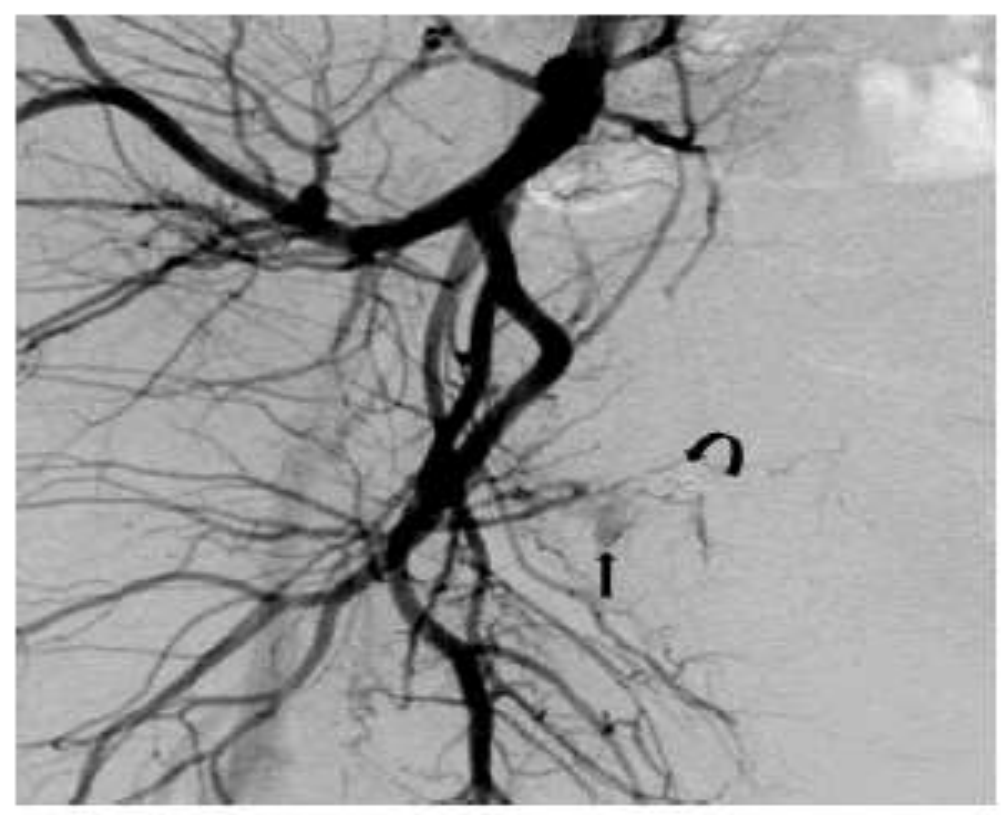

\section{Figure 15:}

Right internal iliac artery catheter angiography done at the time of the second arterial embolization by interventional radiology. Images abnormal blush/ AV fistula (arrow) in the same location to previous embolization site (curved arrow showing the coil). Near stasis of the right uterine artery was noted which was further embolized completely with glue. Reproduced from: [25] Jacques L, Lund M, Baruah D. Uterine Arteriovenous Malformation: A Rare Cause Vaginal Hemorrhage after hysterectomy. Gynecology \& Obstetrics Case Report. 2016; 2(2): 1 - 4. doi:10.21767/24718165.1000029 https://gynecology-obstetrics.imedpub.com/uterine-arteriovenous-malformations-a-rare-cause-of-vaginal-hemorrhage-afterhysterectomy.pdf https://gynecology-obstetrics.imedpub.com/uterine-arteriovenous-malformations-a-rare-cause-of-vaginal-hemorrhage-afterhysterectomy.php?aid=11196

Oh et al. [26] reported a 34-year-old lady which had undergone hysterectomy for uncontrolled post-partum haemorrhage who continued to have hemoperitoneum. Oh et al [26] reported that two days pursuant to her hysterectomy, she developed massive hemoperitoneum which was identified based upon a computed tomography (CT) scan and she had angiography which identified that she had developed acquired arteriovenous malformation (AVM). She was successfully treated by utilization of trans-arterial embolization (TAE) with n-Butyl cyanoacrylate pursuant to her embolization she became haemodynamically stable on the first day pursuant to her embolization and her haemoglobin level was 10.2 grams per decilitre, and she was discharged 4 days thereafter. Oh et al. [26] stated the following:

- Uterine arteriovenous malformation (UVM) which could be congenital or acquired is a relatively uncommon disorder which could cause life-threatening haemorrhage.

- $\quad$ Acquired UVM does tend to occur predominantly pursuant to previous uterine procedures and on rare occasions UVM could occur pursuant to a hysterectomy.

- $\quad$ Even though the best therapeutic option for UVM does remain controversial. Trans arterial embolization (TAE) had recently been introduced as a safe and effective treatment option.

Oh et al. [26] summarized lessons that need to be learnt related to their case report as follows:

- $\quad$ Even though the overall incidence of acquired UVM pursuant to hysterectomy is low, bleeding from acquired UVM should be regarded as one of the differential diagnoses in the immediate post-partum period, particularly when the clinical symptoms do not correlate with the amount of blood loss.

- A high index of suspicion, prompt diagnosis of UVM as well as intervention, and a multi-disciplinary team (MDT) approach with regard to the management represented elements of a successful outcome in their reported case.

A lesson that can be learnt by clinicians is that if AVM (UVM) does occur after a hysterectomy it can be safely and effectively be treated by means of TAE.

Roach et al. [27] reported a 33-year-old lady Gravida 3 Para 3 who had manifested 4 weeks pursuant to caesarean delivery with episodic profuse bleeding from her vagina. She had ultrasound scan of the pelvis and magnetic resonance imaging (MRI) scan of the pelvis which demonstrated a left uterine arteriovenous malformation. She underwent total laparoscopic hysterectomy. Roach et al. [27] stated that acquired uterine arteriovenous malformations and placental ingrowth into the myometrium are increasingly being reported after surgical procedures. Their reported case of a post-partum patient who had uterine arteriovenous malformation as well as retained placenta increta does indicate a correlation between the two complications.

Yan et al. [28] reported a patient who had uterine arteriovenous malformation which was diagnosed based upon magnetic resonance imaging (MRI). She was treated by means of the undertaking of ultrasound scan-guided high-intensity focussed ultrasound (USgHIFU) ablation. The HIFU was effective with regard to the treatment of the uterine arteriovenous malformation. The patient did have reduction in the volume of the lesion and the patient also had obvious relief of her symptoms without any significant adverse effects. Yan et al. [28] iterated the following:

- HIFU can be utilized as a new treatment option for ureteric arteriovenous malformation. 
- Ultrasound scan-guided high-intensity focussed ultrasound ablation is effective for the treatment of uterine arteriovenous fistula.

Rangaran and Moloney [29] stated that uterine arteriovenous malformation (AVM) is not a common problem and that traditionally AVM of the uterus has been treated by hysterectomy which does exclude the possibility of future pregnancy. They iterated that developments in interventional radiology techniques have made the undertaking of transcatheter embolization of feeding vessels, a treatment option alternative to hysterectomy which potentially does preserve the fertility of patients. Rangaran and Moloney [29] reported the case of successful treatment of uterine AVM which had preserved the fertility of a lady.

Przyboiewski and Sadler [30] reported a novel image-guided embolization which had not been previously described in the management of art0eriovenous malformation (AVM) that was resistant to endovascular management. With regard to the details of the procedure, Przyboiewski and Sadler, [30] reported that the uterus was exposed surgically and Histoacryl (Braun, Fulda, Germany) was inserted directly into the nidus with utilization of ultrasound guidance and fluoroscopy. The patient subsequently had a successful full-term pregnancy pursuant to the procedure. Przyboiewski and Sadler [30] iterated that this technique could be a useful alternative treatment option in patients who have AVM of the uterus who fail to respond to traditional endovascular embolization and who still desire to maintain their fertility.

Wijesekera et al. [31] reported two cases of AVMs of the uterus in a patient who had a history of complex congenital heart disease, an association which had not been reported or described. Both patients were treated by the undertaking of selective uterine artery embolization which is a minimally invasive treatment option of AVMs of the uterus and which does offer alternative treatment to conventional hysterectomy.

El Agwany et al. [32] stated that embolization of the uterine artery is the first choice of treatment in symptomatic AVM in patients who are in their reproductive age. El Agwany et al. [32] reported a case of acquired AVMU with an extensive lesion was demonstrated upon ultrasound scan and MRI scan, that was successfully treated by the undertaking of uterine artery embolization (UAE) for profuse bleeding.

McCormick and Kim. [33] stated that AVM of the uterus does cause significant morbidity with vaginal bleeding and that treatment of AVM is hysterectomy which is associated with no potential for future pregnancy. McCormick and Kim. [33] reported a case of successful super-selective embolization of uterine AVM with utilization of n-butyl cyanoacrylate with subsequent normal term pregnancy and uncomplicated vaginal delivery in 1 year.

Barral et al. [34] evaluated the effectiveness of ethylene vicryl alcohol copolymer (Onyx) as a single embolic agent for per-cutaneous arterial treatment of bleeding due to uterine arteriovenous malformations (AVMs). Barral et al. [34] included in a retrospective study twelve women whose mean age was 33A years who had metrorrhagia due to AVMs of the uterus and who had been treated by means of percutaneous arterial embolization of Onyx as a single embolic agent. The diagnosis of AVM of the uterus was suggested based upon pelvic ultrasound scan and / or magnetic resonance imaging (MRI) radiology imaging findings and the diagnosis was further confirmed by the undertaking of angiography. The clinical files of the patients and angiography findings, technical and clinical success, complications of the procedure, as well as further pregnancies were assessed from the data. They defined clinical success by absence of metrorrhagia at $1 \mathrm{~A}$ month pursuant to the embolization. With regard to the results, Barral et al. [34] reported the following:

- Sixteen arterial embolization procedures were undertaken.
- Angiographically, 6 A women had high-flow AVM and 6 women had low-flow AVM.

- $\quad$ The rate of treatment and clinical success rate was $92 \%(11 / 12$ A). One lady who had early repeated bleeding did undergo two (2) embolization procedures and further hysterectomy.

- No severe complications were observed pursuant to embolization.

- Three women out of the 12 women that amounted to $25 \%$ of the patients became pregnant pursuant to the embolization with the inclusion of one full-term pregnancy.

Based upon the results of their study, Barral et al. [34] made the ensuing iterations:

- In women who have metrorrhagia due to AVMs of the uterus, arterial embolization with Onyx is effective as well as safe.

- Additional research is required to confirm the possibility of future pregnancy pursuant to Onyx embolization.

Yoon et al. [35] stated that an acquired uterine artery malformation $(\mathrm{AVM})$ is an uncommon cause of vaginal bleeding and even though hysterectomy is considered to be a definitive treatment, transcatheter embolization (TCE) does provide an alternative option of treatment. Yoon et al. [35] undertook a systematic review which studied the indications, technique, as well as the outcomes of transcatheter treatment of acquired AVMs of the uterus. Yoon et al. [35] screened the literature data bass from 2003 to 2013 for eligible clinical studies which included the characteristics of the patient, the indication for the procedure, the results, the complications, as well as descriptions of the laterality and the embolic agents that were used. Yoon et al. [35] summarized the results as follows:

- They had included a total of 40 studies which had comprised of 54 patients whose average age was 33.4 years.

- $\quad$ TCE had a primary success rate with control of symptoms in $61 \%$ and a secondary success rate of $91 \%$ following repeated embolization.

- When embolization was combined with Medical treatment, resolution of symptom was observed in 48 patients that amounted to $85 \%$ of the patients who did not require more invasive surgical procedures.

Yoon et al. [35] made the following conclusions:

- Low-level evidence does support the role of TCE including in the event of persistent bleeding pursuant to initial embolization for the treatment of acquired AVMs of the uterus.

- The variety of embolic agents and laterality of approach do delineate the pertinence of refining procedure protocols in the treatment of acquired AVMs of the uterus.

Dar et al. [36] reported the clinical and sonography manifestations of 8 cases of AVM of the uterus that had been diagnosed between July 2000 and July 2003. They reported that yearly sonography follow-up was undertaken for a period of 42 months. Dar et al. [36] summarized the results as follows:

- $\quad$ Only 3 of the 8 cases manifested with heavy vaginal bleeding and 2 of them did require selective embolization.

- Two patients out of the 8 patients did undergo hysterectomy during the study period but this was not related to a severe bleeding event.

- Long-term follow-up for all other cases was significant for ultrasound scan resolution of the AVM of the uterus.

Dar et al. [36] made the following conclusions:

- Management of AVMs of the uterus must be influenced by the clinical findings and not based upon the ultrasound scan findings of the AVMU. 
- If it is clinically feasible, conservative treatment must be considered as the primary treatment option, in view of the fact that majority of these lesions do tend to spontaneously resolve.

Yazawa et al. [37] reported a 48-year-old lady who had a past medical history of two abortions and myomectomy who had presented with intermittent massive uterine bleeding. She was diagnosed as having AVM of the uterus based upon trans-vaginal colour Doppler ultrasound scan and helical computed tomography (CT) scan. She had diagnostic threedimensional CT angiogram which clearly did illustrate hyper-vascular tangles of uterine vessels, the feeding arteries, remarkably dilated draining veins, and early filling of free internal iliac vein and inferior vena cava which indicated massive arteriovenous shunting within the uterus. She received danazol for 10 months in order to reduce the shunting of the AVM of the uterus before the undertaking of a successful trans arterial embolization (TAE) with N-butyl-cyano-acrylate of the left ovarian and left uterine artery. Pursuant to the embolization procedure, it was confirmed that the shunting through the arteriovenous malformation of the uterus (AVMU) was markedly reduced. At the time of the report of the case, the patient had not experienced any severe uterine bleeding since her embolization procedure was undertaken.

Sato et al. [38] reported a post-menopausal woman who had arteriovenous fistula of the uterus who did undergo emergency hysterectomy for sudden onset of life-threatening uterine bleeding pursuant to an initially successful but ultimately failed embolization of uterine artery. One year after the hysterectomy, she had not had any further vaginal bleeding. Sato et al. [38] stated that hysterectomy does represent a comparably safe as well as effective treatment for post-menopausal women who have suffered from AVMs of the uterus with life-threatening uterine bleeding. [38]

\section{Conclusions}

- Arteriovenous malformation is a rare condition that has tended to be either congenital AVMU which does occur in fewer cases or it could be acquired AVMU.

- AVMUs do present with various types of abnormal uterine bleeding at various ages that could be mild, moderate, or profuse, intermittent, or continuous.

- Diagnosis of AVMUs have been based upon ultrasound scan / Doppler scanning of the uterus and pelvic region, Contrast Computed Tomography scan of the uterus and pelvic region, Contrast Magnetic Resonance Imaging of the Uterus and Pelvic Region, and Selective angiography that delineates the uterine arteries including the AVMUs.

- Treatment of mild cases of AVMUs have tended to be expectant/conservative with medical hormonal management, hysterectomy has tended to be undertaken in many centres as treatment of curative intent under general anaesthesia with regard to severe and persistent bleeding which though effective has rendered all the patients incapable of maintaining their future fertility, and in centres where there are interventional radiologists and well-equipped interventional radiology departments selective angiography and super-selective embolization of the AVMUs had tended to be undertaken under local anaesthesia with good results that stopped the bleeding as well as which has tended to be associated with reduction in the size of large AVMUs. At times recurrences of AVMU had occurred therefore regular surveillance clinical radiology imaging follow-up and angiography follow-ups are required to ensure maintenance of resolution of the AVMU is confirmed.

- If globally more interventional radiologists could be trained, then eventually selective angiography and super-selective embolization could become the first line treatment option for most cases of moderate to large-sized AVMUs whilst reserving hysterectomy for cases of failed embolization of AVMUs which would reduce the number of ladies who would not be able to maintain their future fertility pursuant to treatment of their AVMUs.

- There are other less invasive treatment options that could be utilized for bleeding AVMUs that have so far not been undertaken and these treatment options could be included in a global multi-centre trial. These suggested alternative treatment options include: (a) radiology image-guided cryotherapy of AVMU, (b) radiology image-guided radiofrequency ablation of the AVMU, and (c) radiology image-guided irreversible electroporation of AVMU.

\section{Conflict of interest- None}

\section{Acknowledgements}

Acknowledgements to.

- Case Reports in Obstetrics and Gynecology and Hindawi Publishing LTD for granting permission for reproduction of figures and contents of their journal article under creative commons licence agreement.

- Obstetrics and. Gynecology. International. Journal and Medcrave Journals Online for granting permission for reproduction of figures and contents of their journal articles under copy right (C2017 Shintre, et al. This is an open access article distributed under the terms of the, which permits unrestricted use, distribution, and build upon your work noncommercially

- Cureus for granting permission for reproduction of figures and contents of their journal article under Copyright (c) 2019, Khan et al. This is an open access article distributed under the terms of the Creative Commons Attribution License, which permits unrestricted use, distribution, and reproduction in any medium, provided the original author and source are credited.

- Gynecology \& Obstetrics Case Report and the authors of the article for granting copyright permission for reproduction of figures and contents of their journal article under a Creative Commons Attribution Licence that allows others to share the work with an acknowledgement of the work's authorship and initial publication in the Gynecology and Obstetrics Case Report Journal.

\section{References}

1. Karadag B, Erol O, Ozdemir O, Uysal A, Alparslan A S, Gurses C, Koroglu M.(2016) Successful Treatment of Uterine Arteriovenous Malformation due to Uterine Trauma. Case Rep Obstet Gynecol. 2016;2016:1890650. doi: 10.1155/2016/1890650. Epub 2016 Sep 6. PMID: 27699074; PMCID: PMC5028872.

2. O'Brien P, Neyastani A, Buckley A R, Chang S D, Legiehn GM.(2006). Uterine arteriovenous malformations: from diagnosis to treatment. J Ultrasound Med. 2006 Nov;25(11):1387-92; quiz 1394-5. doi: 10.7863/jum.2006.25.11.1387. PMID: 17060424.

3. Halperin R, Schneider D, Maymon R, Peer A, Pansky M, Herman A. (2007). Arteriovenous malformation after uterine curettage: a report of 3 cases. J Reprod Med. 2007 May;52(5):445-9. PMID: 17583252.

4. Cura M, Martinez N, Cura A, Dalsaso T J, Elmerhi F. (2009). Arteriovenous malformations of the uterus. Acta Radiol. 
Sep;50(7):823-9. doi: 10.1080/02841850903008792. PMID: 19513893.

5. Grivell R M, Reid K M, Mellor A. Uterine arteriovenous malformations: a review of the current literature. Obstet Gynecol Surv. 2005 Nov;60(11):761-7. doi: 10.1097/01.ogx.0000183684.67656.ba. PMID: 16250925.

6. Polat P, Suma S, Kantarcý M, Alper F, Levent A.(2002). Color Doppler U S in the evaluation of uterine vascular abnormalities. Radiographics. 2002 Jan-Feb;22(1):47-53. doi: 10.1148/radiographics.22.1.g02ja0947. PMID: 11796897.

7. Ghi T, Giunchi S, Rossi C, Pilu G, Savelli L, Mollo F, Pelusi G. (2005). Three-dimensional power Doppler sonography in the diagnosis of arteriovenous malformation of the uterus. J Ultrasound Med. 2005 May;24(5):727-31. doi: 10.7863/jum.2005.24.5.727. PMID: 15840807.

8. Soeda S, Kyozuka H, Suzuki S, Yasuda S, Nomura Y, Fujimori K.(2014) Uterine artery embolization for uterine arteriovenous malformation is associated with placental abnormalities in the subsequent pregnancy: two cases report. Fukushima J Med Sci. 2014;60(1):86-90. doi: 10.5387/fms.2013-13. Epub 2014 Mar 27. PMID: 24670673.

9. Goldberg J, Pereira L, Berghella V. Pregnancy(2002) after uterine artery embolization. Obstet Gynecol. 2002 Nov;100(5 Pt 1):869-72. doi: 10.1016/s0029-7844(02)02347-5. PMID: 12423843.

10. Van den Bosch T, Van Schoubroeck D, Lu C, De Brabanter J, Van Huffel S, Timmerman D. Color Doppler and gray-scale ultrasound evaluation of the postpartum uterus. Ultrasound Obstet Gynecol. 2002 Dec;20(6):586-91. doi: 10.1046/j.14690705.2002.00851.x. PMID: 12493048.

11. Van Schoubroeck D, Van den Bosch T, Scharpe K, Lu C, Van Huffel S, Timmerman D. (2004) Prospective evaluation of blood flow in the myometrium and uterine arteries in the puerperium. Ultrasound Obstet Gynecol. Apr;23(4):378-81. doi: 10.1002/uog.963. PMID: 15065189.

12. Onoyama I, Fukuhara M, Okuma A, Watanabe Y, Nakamura G. (2001) Successful pregnancy after the noninvasive management of uterine arteriovenous malformation. Acta Obstet Gynecol Scand. Dec;80(12):1148-9. doi: 10.1034/j.1600-0412.2001.801216.x. PMID: 11846717.

13. Takeuchi K, Yamada T, Iwasa M, Maruo T.( 2003) Successful medical treatment with danazol after failed embolization of uterine arteriovenous malformation. Obstet Gynecol. Oct;102(4):843-4. doi: 10.1016/s0029-7844(03)00707-5. PMID: 14551016

14. Nonaka T, Yahata T, Kashima K, Tanaka K.( 2011). Resolution of uterine arteriovenous malformation and successful pregnancy after treatment with a gonadotropin-releasing hormone agonist. Obstet Gynecol. Feb;117(2 Pt 2):452-455. doi: 10.1097/AOG.0b013e3181f7381f. PMID: 21252786.

15. Sen S, Talavera F, Kirschner H S, Hogan E L, Webb S, Editors Lutsep H L, Selph J.( 2016) Arteriovenous Malformations Medscape Updated Dec 04

16. Shintre H S, Coelho K S.( 2017). Managing Uterine Arteriovenous Malformation (AVM) Is Like Dealing With Raging Wildfire Awaiting A Spark: Better Be Extremely Cautious \& Be Ready With Counter Measures Like Uterine Artery Embolization (UAE). Obstet. Gynecol. Int. J.; 6(1): 00195

17. Dubreuil G L E.(1926) Aneurysme crisoide de l'uterus. Ann Anat Pathol; 3: 697 - 718.

18. Hashim H, Nawawi O.( 2013). Uterine arteriovenous malformation. Malays J Med Sci. Mar;20(2):76-80. PMID: 23983582; PMCID: PMC3744004.
19. Sridhar D, Vogelzang R L.( 2018). Diagnosis And Treatment Of Uterine And Pelvic Arteriovenous Malformation.Endovascular Today; 17(1): 73 - 77.

20. Yawaza H, Soeda S, Hiraiwa T, Hasegawa-Endo S, Kojima M, Fujimori K. (2013) prospective evaluation of the incidence of uterine vascular malformations developing after abortion or delivery. Journal of Minimally Invasive Gynecol. 2013; 20: 360 $-367$

21. Katimada T, Annaiah T K, Sreenirasan S K. (2015) uterine arteriovenousmal formations: Clinical implications. The Obstetrician \& Gynaecologist 2015 Oct 20; 17(4): 243 - 250.

22. Ore R M, Lynch D, Rumsey C.(2015) Uterine Arteriovenous Malformation, Images, and Management. Military Medicine; 180(1): e177

23. Kim T H, Lee H H.(2010) Presenting features of women with uterine arterio-venous malformations. Fertil-Sterilm; 941: 2330. E $7-10$

24. Khan S, Saud S, Khan I, Achakzai B. (2019) Acquired Uterine Arteriovenous Malformation Following Dilatation and Curettage Treated with Bilateral Uterine Artery Embolization: A Case Report. Cureus. Mar 13;11(3):e4250. doi: 10.7759/cureus.4250. PMID: 31131173; PMCID: PMC6516630.

25. Jacques L, Lund M, Baruah D. (2016) Uterine Arteriovenous Malformation: A Rare Cause Vaginal Hemorrhage after hysterectomy. Gynecology \& Obstetrics Case Report. 2016; 2(2): $1-4$

26. Oh C H, Kim Y, Cho S C, Yi K S, (2021) (editor Suranathan M). Successful transcatheter arterial embolization for massive hemorrhage from acquired uterine arteriovenous malformation which occurred as a complication of hysterectomy. A case report. Medicine (Baltimore) Jan 15; 100(2): e 24052.

27. Roach M K, Thomassee M S. (2015). Acquired Uterine Arteriovenous Malformation and Retained Placenta Increta. Obstet Gynecol. Sep;126(3):642-644.

28. Yan X, Zhao C. Tian C, Wen S, He X, Zhou Y, (2017). Ultrasound-guided high-intensity focussed ultrasound ablation for treating uterine arteriovenous fistula. British Journal of Obstetrics and Gynaecology (BJOG). Aug; 124(53): 93 - 96.

29. Rangaran R D, Moloney J C. (2007)Diagnosis and Nonsurgical Management of Ureteric Arteriovenous Malformation Cardiovascular and Interventional Radiology; 30(6): 30: 1267 -1270 .

30. Przybojewski, S.J., Sadler, D.J. (2011). Novel Image-Guided Management of a Uterine Arteriovenous Malformation. Cardiovasc Intervent Radiol ; 34, 161-166.

31. Wijesekera, N.T., Padley, S.P., Kazmi, F. et al. (2009). Embolization of Uterine Arteriovenous Malformations Associated with Cyanotic Congenital Heart Disease. Cardiovasc Intervent Radiol 2009; 32, 1075-1079 .

32. El Agwany AS, Elshafei M. Extensive uterine arteriovenous malformation with hemodynamic instability: Embolization for whole myometrium affection. Eur J Obstet Gynecol Reprod Biol. 2018 Mar;222:188-191. doi: 10.1016/j.ejogrb.2018.01.018. Epub 2018 Jan 31. PMID: 29395294.

33. McCormick CC, Kim HS.( 2006). Successful pregnancy with a full-term vaginal delivery one year after n-butyl cyanoacrylate embolization of a uterine arteriovenous malformation. Cardiovasc Intervent Radiol. Jul-Aug;29(4):699-701. doi: 10.1007/s00270-005-0202-1. PMID: 16502173.

34. Barral P A, Saeed-Kilani M, Tradi F, Dabadie A, Izaaryene J, Soussan J, Bartoli J M, Vidal V.( 2017). Transcatheter arterial embolization with ethylene vinyl alcohol copolymer (Onyx) for 
the treatment of hemorrhage due to uterine arteriovenous malformations. Diagn Interv Imaging. May;98(5):415-421. doi: 10.1016/j.diii.2016.09.003. Epub 2016 Oct 21. PMID: 27776896.

35. Yoon D J, Jones M, Taani J A, Buhimschi C, Dowell J D. (2016). A Systematic Review of Acquired Uterine Arteriovenous Malformations: Pathophysiology, Diagnosis, and Transcatheter Treatment. AJP Rep. Mar;6(1):e6-e14. doi: 10.1055/s-0035-1563721. Epub 2015 Oct 12. PMID: 26929872; PMCID: PMC4737639.
36. Dar P, Karmin I, Einstein M H.( 2008) Malformations of the Uterus: Long-Term Follow-Up. Gynecol. Obstet. Invest.; 66: $157-161$

37. Yazawa H, Soeda S, Hiraiwa T, Takaiwa M, Fujimori K. A case of severe uterine arteriovenous malformation treated with danazol and followed by a transarterial embolization of unilateral uterine and ovarian arteries. Gynecology and Minimally Invasive Therapy. 2015 Oct 29; 4(4): 149 - 153.

38. Sato E, Nakayama K, Nakamura K, Ishikawa M, Katagiri H, Kyo S. (2015). A case with life-threatening uterine bleeding due to post-menopausal uterine arteriovenous malformation. BMC Women's Health 15(10):
This work is licensed under Creative Commons Attribution 4.0 License

To Submit Your Article Click Here: Submit Manuscript

DOI: $10.31579 / 2578-8965 / 085$
Ready to submit your research? Choose Auctores and benefit from:

$>$ fast, convenient online submission

$>$ rigorous peer review by experienced research in your field

$>$ rapid publication on acceptance

$>$ authors retain copyrights

$>$ unique DOI for all articles

$>$ immediate, unrestricted online access

At Auctores, research is always in progress.

Learn more auctoresonline.org/journals/obstetrics-gynecology-andreproductive-sciences 